IZA DP No. 7905

Timing of College Enrollment and Family Formation Decisions

Maria K. Humlum Jannie H. G. Kristoffersen

Rune Vejlin

January 2014 


\title{
Timing of College Enrollment and Family Formation Decisions
}

\author{
Maria K. Humlum \\ Aarhus University and IZA \\ Jannie H. G. Kristoffersen \\ CEBR, CBS \\ Rune Vejlin \\ Aarhus University and CAP
}

Discussion Paper No. 7905

January 2014

IZA
P.O. Box 7240
53072 Bonn
Germany

Phone: +49-228-3894-0

Fax: +49-228-3894-180

E-mail: iza@iza.org

\begin{abstract}
Any opinions expressed here are those of the author(s) and not those of IZA. Research published in this series may include views on policy, but the institute itself takes no institutional policy positions. The IZA research network is committed to the IZA Guiding Principles of Research Integrity.

The Institute for the Study of Labor (IZA) in Bonn is a local and virtual international research center and a place of communication between science, politics and business. IZA is an independent nonprofit organization supported by Deutsche Post Foundation. The center is associated with the University of Bonn and offers a stimulating research environment through its international network, workshops and conferences, data service, project support, research visits and doctoral program. IZA engages in (i) original and internationally competitive research in all fields of labor economics, (ii) development of policy concepts, and (iii) dissemination of research results and concepts to the interested public.
\end{abstract}

IZA Discussion Papers often represent preliminary work and are circulated to encourage discussion. Citation of such a paper should account for its provisional character. A revised version may be available directly from the author. 


\section{ABSTRACT}

\section{Timing of College Enrollment and Family Formation Decisions ${ }^{\star}$}

The level of progression of an individual's educational or labor market career is a potentially important factor for family formation decisions. We address this issue by considering the effects of a particular college admission system on family formation. We show that the admission system affects mainly the timing of college enrollment and not the college-going decision. As such, we consider a specific type of career interruption and its consequences for relationship formation and fertility decisions. Specifically, we employ a regression discontinuity design based on the college admission system to estimate the effect of being above the admission requirement in the year of application on later family formation decisions. We find that the admission system has substantial effects on the timing of family formation and, specifically, that the timing of college enrollment is an important determinant hereof. This suggests that career interruptions such as delays in the educational system can have large effects on family decision-making.

JEL Classification: $\quad$ I2, J12, J13

Keywords: fertility, education policy, career interruptions, delayed college enrollment, regression discontinuity

Corresponding author:

Maria K. Humlum

Department of Economics and Business

Aarhus University

Fuglesangs Allé 4

8210 Aarhus $\mathrm{V}$

Denmark

E-mail: mhumlum@econ.au.dk

\footnotetext{
* We are grateful to the office of the Coordinated Enrollment System in Denmark for the opportunity to use their database in our work. Maria Knoth Humlum and Rune Vejlin gratefully acknowledge support from The Danish Council for Independent Research - Social Sciences, grant no. 09-068698 and 09066745, respectively. We thank Marianne Simonsen, participants at DGPE 2009, DGPE 2010, the LMDG-BI 2011 meeting, the Empirical analysis of family economics workshop in Ebeltoft, ESPE 2011, IWAEE 2011, and the Workshop on Family and Gender in Honningsvåg, and seminar participants at the University of Copenhagen, Aarhus University, Carnegie Mellon University, and SFI for constructive comments.
} 


\section{Introduction}

Low fertility rates in almost all OECD countries have caused a large demographic shift in recent years. Fertility rates in Italy, Spain, Germany, and Japan are as low as 1.3 children per woman, whereas only the United States, New Zealand, Ireland, Iceland, and France have fertility rates above 1.9 children per woman, see Feyrer, Sacerdote, and Stern (2008). Understanding why we observe lower fertility rates is essential in order to design policies that can help alleviate the problem. The drop in fertility has to some extent coincided with an increase in women's educational attainment, see Goldin and Katz (2002), and there is considerable empirical evidence linking education and fertility decisions, see, e.g., Currie and Moretti (2003) and Black, Devereux, and Salvanes (2008). We contribute to this literature by presenting empirical evidence suggesting that delayed college enrollment has substantial effects on family formation decisions. Since the timing of college enrollment is likely to be correlated with a range of unobservable characteristics, we use a feature of the Danish college admission system to identify the effect of being above the admission requirement in one's preferred college program on family formation outcomes. Further, analyzing how being above the admission requirement affects the timing of enrollment and the choice of specific college programs allows us to make relevant observations about the timing of college enrollment and family formation decisions.

From a theoretical perspective, there are a number of potential explanations why delayed college enrollment would affect family formation decisions. Education is a time-consuming activity, and as such, it may crowd out time spent on other activities including searching for a mate and caring for a child. Becker (1965) proposes a labor supply model in which education increases earnings and thus increases women's opportunity cost of having children. However, as higher education leads to higher permanent income, this could also lead to higher fertility. The literature on the quantity-quality trade-off regarding children generally makes the prediction that fertility is decreasing in education, see Becker and Lewis (1973) and Becker and Tomes (1976). Happel, Hill, and Low (1984) consider a model of the timing of the first birth. Among other things they suggest that prospective parents have an economic incentive to align the costs of having a child with a period of their lives where their income is relatively high if they wish to smooth consumption over their life-cycle and capital markets are not perfect. This is what Happel, Hill, and Low (1984) 
term the "consumption-smoothing motive in child-timing decisions". Since household income will tend to increase substantially when one or both wage earners complete their education and enter the labor market, the presence of this consumption-smoothing motive implies that the timing of college enrollment may affect the timing of family formation. Also, if there is uncertainty about getting a job after completing college, or uncertainty about the wage in the potential job, then a risk-averse prospective parent may want to postpone family formation until having procured the first job. It may also be that women prefer to delay childbirth until they have reached certain career-related milestones due to social norms. This mechanism would probably be especially important for career-oriented and highly-educated women, who are likely to be over-represented in our sample of college applicants.

Delayed college enrollment has become increasingly widespread in recent years in many countries. Cammelli, Antonelli, di Francia, Gasperoni, and Sgarzi (2011) report that prior to 2001, 11 percent of Italian high school graduates delayed enrollment, while in 2008 this was more than doubled. Holmlund, Liu, and Skans (2008) find that 27 percent of Swedish college entrants in 2000 had delayed enrollment by two to four years. Furthermore, over the period from 1977 to 2002 the median number of years between high school graduation and college enrollment was 3. Based on the National Educational Longitudinal Study, Bozick and DeLuca (2005) establish that 16 percent of high school graduates in the US postpone college enrollment by more than seven months. In addition, Horn, Cataldi, Sikora, and Carroll (2005) report that the proportion of undergraduates who delay enrollment has increased over the past decade in the US. ${ }^{1}$ Delayed enrollment thus appears to be an increasingly important type of career interruption, not only in continental Europe, but also in the US.

Our study is closely related to the literature on the relationship between educational attainment and family formation. This literature has documented a strong link between the two. In order to establish whether this is indeed a causal link, some studies have used exogenous variation in educational attainment generated by rules regarding age at school entry and compulsory schooling laws. For school entry rules, the existing evidence is somewhat mixed. Using data from birth

\footnotetext{
${ }^{1}$ In the 1999-2000 school year, 46 percent of undergraduate students did not start their post-secondary schooling the same calendar year that they completed high school according to Horn, Cataldi, Sikora, and Carroll (2005). Their sample is based on all students aged $18-56$.
} 
records from Texas and California McCrary and Royer (2011) find little effect of mother's education on fertility outcomes. However, using a similar approach, Skirbekk, Kohler, and Prskawetz (2004) find positive effects on the age at first and second birth and age at first marriage for Swedish women, while Black, Devereux, and Salvanes (2011), using Norwegian data, find little impact of school starting age on educational attainment, but some impact on teenage pregnancies.

Compulsory schooling laws have been used to instrument educational attainment to study the effects of education on various outcomes. Focusing on family formation outcomes, there is a substantial amount of evidence suggesting that educational attainment affects fertility and marriage choices. Whether or not the effects on family formation decisions are temporary, e.g. affecting only the age at first birth, or permanent, e.g. affecting completed fertility, appears to remain an open question though. While Monstad, Propper, and Salvanes (2008) use Norwegian data and find little effect on completed fertility, Fort, Schneeweis, and Winter-Ebmer (2011) use data from eight European countries and find that more education actually increases completed fertility. Also, increasing the length of compulsory schooling reduces the incidence of teenage pregnancies, see Black, Devereux, and Salvanes (2008) for Norway and the U.S. or Silles (2011) for Great Britain and Northern Ireland. Devereux and Tripathi (2009) find that increasing the length of compulsory schooling increases age at first marriage.

To find exogenous variation that changes the length of education at higher levels in the educational system is much more rare. Obviously, the mechanisms and potential effects of education are also likely to be different. Currie and Moretti (2003) use college openings as an instrument for education and find that increasing education reduces completed fertility. More recently, Grönqvist and Hall (2013) use a Swedish reform that prolonged vocational tracks from two to three years among other things. They find that the reform reduced early fertility. Overall, there appears to be a consensus that educational decisions and thereby educational policy affect many important life decisions including family formation decisions.

We contribute to the current literature along several dimensions. First, we use a very different source of exogenous variation than existing studies, namely college admission requirements. Thus, we use exogenous variation that affects individuals at a much later stage in life than almost all of the studies mentioned above. This type of variation is interesting to study from a policy 
perspective, since— to a large extent—it is a policy choice whether or not to encourage immediate enrollment in college. Secondly, we show that being above the admission requirement affects mainly the timing of college enrollment indicating that timing really is the channel through which the admission system affects family formation. This is opposed to many of the studies using school starting age as an instrument. The main point in these studies is that years of education is an important determinant of fertility. We argue that there may be an additional mechanism through which school starting age and educational policy in general affect fertility, namely the timing of educational progression. We show that individuals who are affected by the admission system are induced to postpone their college entry, but not alter their college-going decision as such. Therefore, we interpret our estimates as reflecting primarily a timing effect and not a human capital effect. Finally, we contribute to the literature on career interruptions and the effects hereof.

In our empirical analysis, we use the setup of the Danish college admission system to analyze how this interrelates with college enrollment and family formation decisions. Using a regression discontinuity design, we estimate the effect of being above the admission requirement on later family formation decisions. ${ }^{2}$ To the extent that the admission system affects only the timing of college enrollment, we estimate the effect of a particular type of career interruption on the timing of fertility and relationship formation. Danish colleges are capacity constrained, and a centralized admission system ensures that the most able applicants in terms of high school GPA are allocated to their preferred college programs, resulting in an effective grade requirement (henceforth the admission requirement) for each college program in each year. Applicants with a GPA above the requirement are admitted, and applicants with a GPA below the requirement are rejected. ${ }^{3}$ Since the admission requirements are unknown to applicants when they apply, the admission system is a potential source of exogenous variation in college-going decisions, such as the timing of enrollment and the choice of college program.

In order to interpret the effects of being above the admission requirement on fertility and marriage, we also consider how college enrollment, college completion, and earnings are affected. Overall, these results suggest that the admission system affects mainly the timing of college en-

\footnotetext{
${ }^{2}$ See Öckert (2010) for an example of a study using a college admission system to identify causal effects of education on earnings.

${ }^{3}$ In reality the admission system is more complex. Additional details are given in section 2 .
} 
rollment. We find substantial effects of being above the admission requirement on family formation outcomes. The pattern of the estimates is consistent with a setting in which the level of progression in the educational system affects family decision-making. Thus, our analysis suggests that later college entry leads to delays in family formation and possibly also to long-run differences in family size. Compared to the literature using school starting age, we find much larger effects on family formation outcomes.

Even though our estimates suggest relatively large effects of delayed enrollment, the macrolevel effects might be even larger. Feyrer, Sacerdote, and Stern (2008) argue that if large peer effects exist in fertility choices, even individual-level effects might have large effects on the macro level. Ciliberto, Miller, Nielsen, and Simonsen (2013) find evidence that peer effects in fertility exist at the workplace, while Kuziemko (2006) presents evidence on sibling peer effects in fertility choices. In the presence of peer effects, our individual-level estimates represent a lower bound of the macro-level effect.

The paper is organized as follows. In section 2 the institutional settings and the Coordinated Enrollment System for colleges in Denmark are described. In section 3 we outline our empirical approach. Section 4 describes the data used, and in section 5 we present our estimation results. Finally, section 6 concludes.

\section{Institutional settings}

In Denmark compulsory schooling has a duration of 9 years, and children usually start school at the age of seven. ${ }^{4}$ After compulsory school further education can be obtained by attending either a vocational education and training program or a high school program. In high school, the students can choose between a business track, a technical track, or an academic track. High school programs and to a smaller extent vocational programs serve as qualifying educations for entering college programs. The costs of going to college are negligible in Denmark compared to, for example, the US, as college programs are free and publicly provided, and very generous

\footnotetext{
${ }^{4}$ In 2009 this was changed to 10 years of compulsory schooling starting at the age of six.
} 
student grants are provided by the government. ${ }^{5}$ It is also possible to take up additional student loans at favorable terms. In general, the student grant is set to cover living expenses.

\subsection{The Coordinated Enrollment System}

All applications to college programs in Denmark are handled by a centralized admission system, the Coordinated Enrollment System (CES). The applicant can apply to up to eight different college programs in the same application. For a large number of college programs there are more applicants than available slots, which implies that college applicants are potentially constrained in their choice of college programs.

CES allocates applicants to college programs such that the best applicants are allocated to their preferred college programs. The system is complex, but the majority of applicants are assessed exclusively on their high school GPA. In addition, each college program has some basic requirements that mainly consist of high school course requirements. Each college reports to CES how many slots they have in each program. The applicants are ranked according to their high school GPA. Higher-ranking applicants are admitted, and the admission requirement for a particular college program is set at the GPA of the marginal applicant. An applicant with a GPA above the admission requirement is offered a slot, whereas an applicant with a GPA below the admission requirement is rejected. In this way, the admission requirement for each college program is determined each year after the application deadline. Even though the number of slots in each program varies little from year to year, the number of applicants varies, which means that the admission requirement varies. Thus, applicants do not know the admission requirement at the time they apply, and at least for individuals with a GPA close to the admission requirement, it will not be possible to predict whether the admission requirement of a given college program will be above or below their GPA. ${ }^{6}$

Many programs use a simple admission rule for applicants with a GPA equal to the admission requirement; they simply offer admission to all of these applicants. Another common rule is an age tie-breaking rule. The rule implies that when two applicants are tied with respect to GPA,

\footnotetext{
${ }^{5}$ In 2010 the student grant for a student not living at home was DKK 5,384 corresponding to approximately USD 900 per month.

${ }^{6} \mathrm{We}$ document the time variation in the admission requirements in section 4.3 .
} 
the oldest applicant is admitted. In addition, some college programs use other types of admission rules for these marginal applicants. In the empirical analysis, we focus on programs that offer admission to all applicants with a GPA equal to the admission requirement.

As previously mentioned, some applicants are assessed on other characteristics besides their high school GPA. One can apply based on a point system, which gives points partly for the GPA from the qualifying education and partly for other activities such as relevant work experience, stays abroad etc. The slots in a given year allocated to such applicants constitute a minor part of the total number of slots.

The system also allows applicants to apply for standby slots, i.e., the applicant is guaranteed a slot in the next academic year at the latest. These slots are allocated to applicants who have a GPA slightly below the admission requirement. For college programs that offer standby slots, a standby requirement will be determined along with the admission requirement. The existence of the standby slots implies that individuals who are just below the admission requirement are likely to enroll in their preferred college program within a year of their original application, if they have applied for a standby slot. Standby slots are used extensively and especially at the college programs that we include in the estimation sample. For example, the ratio of standby slots to regular slots across relevant college programs at the largest university in Denmark in 2001 was about 10 percent.

\section{Empirical Approach}

The empirical approach is inspired by the institutional settings described above. The basic idea is to use the fact that applicants at the time of application cannot perfectly predict what the admission requirement is going to be in a given college program. The underlying assumption behind the identification strategy is that applicants who end up being just above or just below the admission requirement are essentially the same ex ante. If the admission requirement for an applicant's preferred program turns out to be above the applicant's GPA, there is a much lower chance of being admitted to that program in that year than if the admission requirement turns out to be below the applicant's GPA. Thus, one can think of this as a set of fuzzy regression discontinuities 
$(\mathrm{RDs})^{7}$, if one considers each college program in each year separately.

Let $d_{i}$ measure the distance from the admission requirement of individual $i$ 's preferred college program to individuals $i$ 's high school GPA.

$$
d_{i}=G P A_{i}-A R_{i} \quad\left\{\begin{array}{l}
<0 \Rightarrow t_{i}=0 \\
\geq 0 \Rightarrow t_{i}=1
\end{array}\right.
$$

where $G P A_{i}$ is the high school GPA for individual $i$, and $A R_{i}$ is the admission requirement at individual $i$ 's preferred college program. We will refer to $d_{i}=0$ as the discontinuity point. Under the assumption that applicants cannot perfectly predict the admission requirement, $t_{i}$ will only be correlated with later outcomes to the extent that it affects college-going decisions, such as the timing of enrollment and the choice of college program. Thus, for applicants with distances sufficiently close to zero, we can estimate the causal effect of being above the admission requirement of one's preferred college program $\left(t_{i}=1\right)$ on later outcomes. Our focus is on family formation outcomes, but in order to explore the mechanisms behind our results, we will also analyze how being above the admission requirement affects college enrollment, completion, and labor market earnings.

For an individual $i$ with preferred college program $k$ in year $t$, we consider the following outcome equation,

$$
y_{i}=f\left(d_{i}, t_{i}\right)+X_{i} \beta+\theta_{t k}+\gamma t_{i}+\varepsilon_{i}
$$

where $y_{i}$ is the outcome. $f$ is a function such as splines or polynomials approximating the underlying variables. Specifically, we will allow for the effect of $d_{i}$ to vary by whether an individual is above or below the admission requirement. $X_{i}$ is a vector of control variables such as age, gender, parental background etc. $\theta_{t k}$ is a preferred program-year fixed effect (program $k$ in year $t$ ). For example, there will be a separate fixed effect for applicants who prefer to enroll in Medicine at a particular college in a particular year. This captures differences across time and college programs and underlines the fact that we are essentially pooling $K \times T$ (No. of college programs $\times$ No. of time periods) regression discontinuities. Finally, $\gamma$ is the parameter of interest.

\footnotetext{
${ }^{7}$ See Imbens and Lemieux (2008) for a useful methodological overview of regression discontinuity designs.
} 
We will refer to the estimates of $\gamma$ as reduced form estimates. To account for the fact that the individual error terms, the $\varepsilon_{i}$ 's, may be correlated within college programs, we generally cluster standard errors at the college program level.

We estimate the effect of being above the admission requirement in the year of application on later family formation decisions. Hence, the year of application (henceforth abbreviated by YOA) is the obvious reference point, and we consider marriage and parenthood $x$ years after YOA. In this sense, we estimate a series of parameters, $\gamma_{x}$, corresponding to a series of outcomes, $y_{i x}$. In order to be more specific about the ages at which we are looking, we also consider marriage and parenthood at specific ages. Since there is some variation in the age of the applicants in the YOA, the resulting estimates based on outcomes at specific ages are to some extent blurred. This will especially hold true, if family formation decisions are indeed based on the stage of career that the individual is at.

\section{Data}

The data used for the empirical analysis are administrative data hosted by Statistics Denmark and cover the entire Danish population. These data are linked to data from the Coordinated Enrollment System (CES) for college programs in Denmark. The combined data set contains detailed information on young individuals, their college-related choices and preferences, and their educational and family background.

The CES data contains information on all applications to college programs in Denmark in the period 1996-2006. The data thus provides information on all individuals who intended to enroll in college during this period. Since a college application to CES includes a prioritized list of college programs, we can distinguish between the applicants' actual college choices and their stated college preferences.

\subsection{Description of the Sample}

To obtain a suitable sample for the analyses described in the empirical section, we introduce a number of restrictions on the data. Table 1 provides an overview of the sample selection. The data 
contains information on about 600,000 applications to college programs in the period 1996-2006.

We focus on the first application ${ }^{8}$ where the preferred program is a long-cycle college program. ${ }^{9}$ By using only the first application, we ensure that the sample is more homogenous and we avoid giving more weight to individuals who apply repeatedly. It is a requirement for our empirical strategy that the preferred program has a grade requirement, i.e., that the admission requirement is a grade requirement, and, in addition, that the preferred program has a simple enrollment rule for the marginal applicants, cf. section 2. Whether or not a particular college program has a grade requirement can vary from year to year depending on the number of applicants relative to the number of slots. To be included in the sample, the preferred program has to have a grade requirement in the YOA. In other words, the capacity constraint for the preferred program has to be binding in that year. From Table 1, it is clear that the vast majority of individuals apply to programs with a grade requirement. However, many programs do not have a simple enrollment rule for marginal applicants.

In order to compute the distance to the admission requirement for each individual applicant, information about the high school GPA is required. The GPA is missing for a number of applicants which is mainly explained by the presence of applicants with a foreign high school degree or other types of qualifying education where the GPA was not registered.

In order to obtain a relatively homogenous sample in terms of age-which is arguably a very important factor in fertility decisions-we focus on applicants who were 20 years old or younger when they applied. Younger applicants are more likely to be affected by the admission system since they are less likely to have formed relationships and families at the time of application. Later, we will compare the results for young applicants with the results for older applicants.

After imposing all of the above restrictions on the sample, 19,327 observations remain. These include all applications that satisfy the above criteria, but as argued above, the empirical strategy is only valid for applicants whose GPA is in the vicinity of the admission requirement of their preferred program in the YOA. In the main analyses, a window of 0.3 is considered, i.e., 6,313

\footnotetext{
${ }^{8}$ Since we only have application data from 1996 onwards, we cannot be sure that we can identify the first application. We therefore impose the additional restriction that only individuals who graduated high school in 1995 or later are included in the sample.

${ }^{9}$ Long-cycle college programs are programs at university level.
} 
observations. ${ }^{10}$ Figure 1 shows the distribution of the distance from the admission requirement to the high school GPA before imposing the window restriction. The distribution is centered slightly to the left of zero and resembles a normal distribution. We highlight two features of this graph. First, there is a lot of variation around zero, so the window of 0.3 does not seem to be unreasonable. Secondly, there is no sign that individuals bunch just to the right of zero. This indicates that individuals cannot perfectly predict the admission requirement.

\subsection{Descriptive Statistics}

Given the restrictions imposed on the data, the estimation sample cannot be considered a random sample of college applicants. It consists mainly of applicants for relatively prestigious college programs at the two largest universities in Denmark. Table 2 shows the sample means for the included control variables, some relevant application and enrollment variables, and six selected outcomes by whether an individual was above or below the admission requirement. As suggested by Lee and Lemieux (2010), we test for covariate balance by estimating the size of the jump at the discontinuity point for each covariate separately. Specifically, we regress each covariate on $t_{i}$, $d_{i}$, and their interaction including preferred college program-year fixed effects. In the table, we report the coefficient on $t_{i}$ and the corresponding p-value. This exercise reveals a few significant jumps in the control variables—-mainly for some of the indicators for missing data-but overall our interpretation is that covariates appear to be fairly balanced for individuals below and above the admission requirement. In addition, we run a joint test of covariate balance by estimating a set of seemingly unrelated regressions, where each covariate is regressed on $t_{i}, d_{i}$, and their interaction. A test of the null of all coefficients on $t_{i}$ being equal to zero cannot be rejected, and the p-value is about 0.40 .

The statistics in Table 2 highlight that this is not a representative sample of young individuals. Almost 70 percent of the applicants are young women. The average age of the applicants is 19.6 years. Their parents tend to be well-educated. More than 50 percent of both mothers and fathers have a college degree. In addition, the high school GPA which is listed with the college enrollment variables is on average about 9 for this sample, which is considerably above the general

\footnotetext{
${ }^{10}$ See section 4.3 for further discussion of the choice of the size of the window and section 5.5.1 for a robustness check.
} 
average in a high school cohort. ${ }^{11}$ Like the above covariates, the GPA does not appear to jump discontinuously at the discontinuity point. A division of applicants by the field of their preferred college program reveals that about 40 percent of the applicants prefer to enroll in a program in Social Science. Slightly less apply for a college program within Humanities and Health Science, and Natural Science is the least popular choice for the applicants in the sample.

In order to understand the mechanisms through which the admission system affects individuals' college-going behavior, we also consider different college enrollment outcomes. For this purpose, we focus on the four outcomes listed in Table 2: Enrolled in YOA, enrolled in YOA or later, enrolled in preferred college program in YOA, and enrolled in preferred college program in YOA or later. From this we can see some preliminary evidence that the admission system affects enrollment decisions. First, 42 percent of individuals below the admission requirement enroll in college in the YOA compared to 86 percent of those above the admission requirement. Testing for a jump at the discontinuity point, we can strongly reject that the jump is zero. The picture changes when we consider college enrollment in YOA or later. The figures do not suggest that there is a substantial difference in the probability of ever enrolling in college across the two groups. We also consider enrollment in one's preferred college program and see a similar pattern. We will explore these differences in enrollment further in section 5.1.

Generally, we consider the following three family formation outcomes: Being a parent, number of children, and being married. We measure each outcome $x$ years after YOA and at age $a$. Table 2 includes just the above three outcomes 5 years after YOA and at age 26. Based on these, there is some initial indication that individuals above the admission requirement move faster into parenthood. In Denmark premarital cohabitation is widespread and therefore marriage is not the best indicator for family formation, but we include this outcome in lack of a better measure. Figure 2 shows how the probabilities of these outcomes evolve over time for the estimation sample. Generally, the probability of being a parent and the probability of being married are close to zero for very young individuals or around the YOA. The probabilities are increasing and at age 30, 40 percent are parents and 30 percent are married. The picture is roughly the same 10 years after

\footnotetext{
${ }^{11}$ The GPA is not included as a covariate in the estimations as the distance to the admission requirement and the GPA measure the same thing when we include college program-year fixed effects. For the same reason, we do not include indicators of YOA.
} 
YOA. Similarly, the average number of children is close to zero at young ages or around the YOA.

Subsequently it increases steadily and reaches one when individuals are in their early 30s or 13 years after YOA. Clearly, the time period covered constitutes a stage in these individuals' lives where family formation is important.

\subsection{Time Variation in Admission Requirements}

If applicants are able to predict the admission requirement of their preferred college program in the YOA, applicants who are above and below the admission requirement are likely to be systematically different. It is therefore of interest to know how much the admission requirements vary from year to year. To this end, we compute the mean absolute change and the standard deviation of the absolute change in the admission requirement for each program in each year. The unweighted mean absolute change is about 0.33 and the corresponding standard deviation is 0.49 . In order to find a measure that is more relevant in terms of the individuals in the estimation sample, we compute a corresponding weighted mean. The weights used are based on the number of applicants in the estimation sample that applies to a given program in a given year. The weighted mean absolute change is considerably lower than the unweighted mean at about 0.17 with a corresponding standard deviation of 0.27 . This mean absolute change corresponds to a yearly change of approximately 2-4 percent, which implies that potential applicants will not be able to perfectly predict the admission requirement in the year they apply. The standard deviations are also quite high, which again makes it harder for potential applicants to forecast the admission requirement. Presently, these measures should be considered relatively conservative, as changes in admission requirements that reflect a change from a non-binding capacity constraint to a binding capacity constraint are not included. Such changes in admission requirements would tend to be larger. The estimation results will be based on applicants whose distance from the admission requirement to their GPA is -0.3 to 0.2 which we consider a reasonable window in light of the time variation in the admission requirements. However, as this is a crucial assumption in the analysis, the robustness of results with respect to this assumption will be investigated in section 5.5.1. 


\section{Results}

A natural first step of our analysis is to investigate how the admission system affects enrollment decisions by estimating the effect of being above the admission requirement on different measures of enrollment. We hypothesize that the admission system affects enrollment decisions and through these has effects on later family formation decisions. Once we have established how the admission system affects college enrollment, we proceed with the main analyses where we estimate the effect of being above the admission requirement on family formation outcomes. Subsequently, we discuss the potential mechanisms behind the effects in more detail and present some robustness checks. $^{12}$

\subsection{How Does the Admission System Affect Enrollment Decisions?}

Based on the setup of the centralized admission system in Denmark, we hypothesize that the admission system—specifically, being above the admission requirement—potentially affects mainly three aspects of the college-going decision: Whether or not to enroll in college at all, the choice of specific college program, and the timing of college enrollment. Figure 3 shows how the collegegoing decision is affected by being above the admission requirement of one's preferred college program. Each graph plots a measure of college enrollment against distance from the admission requirement. These graphs confirm the picture we saw in Table 2. The probability of enrolling in college in the YOA and the probability of enrolling in one's preferred college program in the YOA both jump discontinuously at the discontinuity point. In comparison, the probability of ever enrolling in college clearly does not, although it does appear to have a kink at the discontinuity point. This suggests that the admission system does not discourage individuals from attending college, but that it does affect the timing of college enrollment. The linear fit is obviously not particularly good for the probability of ever enrolling in one's preferred college program, and based on the graph it is hard to argue that this probability jumps discontinuously at the discontinuity point. Overall, the graphical analysis suggests that the admission system affects mainly the timing of college enrollment and maybe-to some smaller extent- the choice of specific college

\footnotetext{
${ }^{12}$ Unless otherwise stated, the presented results are for a window of 0.3 , i.e., for distances to the admission requirement of -0.3 to 0.2 .
} 
program.

Why is it that we do not see a discontinuity in the probability of ever enrolling in the preferred college program? If we imposed a more flexible fit on the data instead of a linear fit, we would see a roughly continuous but kinked curve. There are two particular features of the admission system that we believe could generate this type of pattern. The first is that individuals can gain admission based on other criteria than the GPA, but the GPA may still carry some weight in the admission decision. This would generate the upward slope in the probability of enrolling in one's preferred college program to the left of the cutoff. It would not necessarily generate the polynomial shape in the probability of ever enrolling in one's preferred college program. However, the presence of standby slots for individuals just below the admission requirement is likely to generate such a pattern. If individuals just below the admission requirement are offered standby slots, being above the admission requirement will not affect your chance of being admitted to your preferred college program, only the timing of admission.

The vertical discontinuity in the probability of enrolling in college in the YOA is about 45 percentage points. This means that being above the admission requirement increases the probability of college enrollment by about 45 percentage points. Individuals who are not admitted to their preferred program may still be admitted to another college program. The probability of ever enrolling in college tends to be increasing in the distance from the admission requirement. This is consistent with higher GPA individuals being more likely to enroll. Even for individuals below the admission requirement, the college enrollment rate is above 95 percent. Individuals below the admission requirement have a positive probability of enrolling in their preferred college program nonetheless. This is due to the fact that individuals who are below the admission requirement can be admitted to their preferred program given that they meet a number of other criteria as mentioned briefly in section 2. Also, individuals above the admission requirement have a probability of enrolling in their preferred college program of less than 0.8. Again, there are a couple of potential explanations for this. First, individuals may decide not to enroll after all, even if offered a slot. Second, individuals may fail to meet some of the other official requirements, e.g., the high school course requirements.

Acknowledging the fact that the admission system may have heterogeneous effects on prospec- 
tive students, we estimate the size of the discontinuous jumps in enrollment for both the estimation sample and for various subsamples that we shall consider in the empirical analysis. In Table 3 , we report the estimated jumps for the four enrollment outcomes for various subgroups. For now, we note that for almost all subgroups, we observe a pattern similar to that observed in the estimation sample: The admission system affects whether you enroll in the YOA, but not whether you ever enroll. $^{13}$

\subsection{How Does the Admission System Affect Family Formation?}

Now that we have an understanding of how enrollment decisions are affected by the admission system, we proceed with the analysis of the effects of the admission system on family formation decisions. First, we analyze in depth the effect on the three family formation outcomes at two specific points in time, namely at age 26 and 5 years after YOA. Next, we proceed by estimating the reduced form model for all ages and years after YOA for each outcome. ${ }^{14}$

By analyzing the effects at age 26 and 5 years after YOA, we do not consider the points in time where the estimated effects are largest, as will be evident later. However, we have chosen points in time where Figure 2 suggests that many individuals have begun making family formation decisions. In addition, 5 years after YOA, many individuals will have graduated from college.

Figure 4 provides a graphical illustration of how the RD strategy works for these selected outcomes. Note that the graphs are plotted for a window of 0.5 which differs from that of the estimation sample. The figure shows a graph of each outcome by distance from the admission requirement. For marriage, these graphs do not suggest any substantial effects of being above the admission requirement. For being a parent or the number of children, the graphs are consistent with the hypothesis that the admission system affects family formation. Particularly, being above the admission requirement appears to have a positive effect on being a parent and number of children both 5 years after YOA and at age 26 .

\footnotetext{
${ }^{13}$ The subgroup of individuals who are 21 years or older when they apply are not part of the estimation sample which includes only young applicants, cf. Table 1.

${ }^{14}$ Of course, it would be preferable to present both graphical evidence and detailed estimation results for outcomes measured at every point in time. However, due to spatial considerations we present only graphical evidence and detailed estimation results for a subset of outcomes. Detailed estimation results are available upon request for every outcome at every point in time.
} 
Table 4 shows the reduced form estimates for the selected outcomes with different conditioning sets. The preferred specification is specification (5) with all controls. The estimates are very insensitive to the inclusion of controls. This is reassuring as it suggests that the RD assumption of covariate balance below and above the admission requirement is reasonable. Taking a closer look at the estimates for marriage, the estimated effects of being just above the admission requirement on the probability of being married at age 26 and 5 years after YOA are 1.8 and 1.0 percentage points, respectively. This indicates that family formation starts earlier for those who are just above the admission requirement. However, for the marriage outcomes, the estimates are generally insignificant. A clearer picture emerges when we consider the effects on the probability of being a parent and the number of children. These estimates are generally relatively large and statistically significant at the 1 percent level. Being above the admission requirement increases the probability of being a parent by 6.2 and 3.9 percentage points at age 26 and 5 years after YOA, respectively. Given that only about 10 percent of individuals in the sample are parents at age 26 and 5 percent 5 years after YOA, being above the admission requirement increases the probability of being a parent at these specific points in time by more than 50 percent. For number of children, the conclusion is similar, and coefficients are of the same order of magnitude. This is to be expected since many individuals in the sample will at most have one child at, for example, age 26 . In the long run, it will be of interest to see whether the effects on these two parenthood outcomes differ.

In order to get a clear overview of how the timing of family formation is affected by the admission system, Figure 5 shows the reduced form estimates for each of the three outcomes plotted against years after YOA or age. Thus, these are estimates of the effect of being above the admission requirement on the entire range of family formation outcomes that we consider.

First, considering the effects on the probability of being married, we see that the estimates tend to be imprecise, but the overall pattern suggests that individuals who are above the admission requirement get married earlier. However, this positive effect disappears around 11 years after YOA. But, for example, around 8 years after YOA individuals who were above the admission requirement are more likely to be married. For age, the pattern is similar with a peak at age 29.

For the two parenthood outcomes, we see that individuals who were above or below the admission requirement tend to have similar tendencies to have children one to three years after YOA. 
But already four years after YOA, we find significant effects on the probability of being a parent and number of children. This positive effect continues to increase until about 10 years after YOA. For being a parent, the estimates again hover around zero about 12-14 years after YOA. These estimates are highly insignificant though. A similar pattern is seen for age. Also in this case, the effect appears to reach a maximum around age 27 after which it goes to zero. The main difference between the graphs for being a parent and number of children is that the dramatic decline in the estimates in the longer run described above, cannot be seen when we consider number of children. ${ }^{15}$ There is a small decline in the estimated effect from age 31 to age 32 , but the confidence intervals are also very wide. Even though we cannot follow the individuals in the sample long enough to draw definitive conclusions about completed fertility, we take this to be suggestive evidence that being above the admission requirement affects completed fertility as well as the timing of the first child. Often the decisions about the timing of the first child and completed fertility are considered linked, see e.g. Björklund (2006). D'Addio and d'Ercole (2005) remark that delays in family formation lead to decreases in fertility rates as well as increased health risks for mothers and their children and increases in the extent of childlessness. In the medical literature, postponement of childbearing has also been linked to changes in total fertility and involuntary childlessness, see Leridon and Slama (2008) and te Velde, Habbema, Leridon, and Eijkemans (2012). Thus, delayed family formation is likely to be associated with both economic and psychological costs.

\subsubsection{Subgroup Analysis}

The admission system potentially affects different subgroups differently. We address this point by dividing the sample into different subgroups that we believe might be differentially affected. ${ }^{16}$ In order to interpret differences in estimated effects across subgroups, it is important to keep in mind that there may be heterogeneous effects on enrollment decisions across subgroups. For example, a small effect on being a parent for a particular subgroup could be due to this subgroup being less affected by the admission system in terms of enrollment. In Table 3 we showed the

\footnotetext{
${ }^{15}$ Given the similarity of the results for being a parent and number of children, we will focus on number of children in the remaining part of the analysis.

${ }^{16}$ We have shortened the time period considered in these graphs since the breadth of the confidence bands would otherwise make the graphs very hard to read.
} 
estimates of being above the admission requirement on four different enrollment outcomes for each of the subgroups that we consider below. For some subgroups, there appears to be only slight differences. This is especially true for gender. Figure 6 shows that there is a tendency for the estimates on parenthood to be larger for women than for men, although the difference is never statistically significant for any one year. Since women's careers are usually more affected by childbearing than men's careers, it makes sense that any effects of the admission system would be larger for women than for men. In comparison, the estimated effects on marriage are roughly the same for men and women.

In the main analysis, we disregard old applicants, i.e. applicants that are 21 years or older when they apply. The results in Table 3 illustrate that the old applicants are affected somewhat differently by the admission system than their younger counterparts. In particular, being above the admission requirement increases the probability of enrolling in the YOA by about 56 percentage points for young applicants, but only about 27 percentage points for old applicants. A potential explanation is that it is likely to be more costly for old applicants to delay enrollment. Therefore, the admission system affects these individuals less in terms of timing, but more in terms of the specific college program attended. Figure 7 shows the reduced form estimates for young and old applicants. For old applicants, the estimated effects are never statistically different from zero and the confidence intervals are very wide. We can think of three main explanations for this. First, they constitute a more heterogeneous group. Second, they are less affected by the admission system in terms of timing of enrollment decisions, and finally, they are more likely to have already made their family formation decisions.

In Figure 8 we present the results by the field of the preferred college program. Again, the results for each subgroup are never significantly different, but there is a tendency that the positive results on parenthood are driven by those who preferred a college program within Medical Science and to some extent Social Science. Table 3 also reveals that these tend to be the two groups that are most affected by the admission system in terms of enrollment decisions. For example, for applicants who prefer a program within Natural Science being above the admission requirement only increases the probability of enrollment in the YOA by about 35 percentage points. Many programs within Natural Science have no GPA requirements due to low popularity making it 
easier for students to substitute between programs.

Another hypothesis could be that applicants are differently affected by the admission system depending on the popularity of the preferred college program. To investigate this issue, we split the sample into applicants who applied to a college program with an admission requirement below or above the median. In terms of enrollment Table 3 shows that the two groups are relatively similar. As one would expect, being above the admission requirement has the largest effect on enrollment in the YOA for applicants to the most popular programs. Figure 9 plots the estimated effects for the two subgroups. Based on the graphs, we do not find evidence of any substantial differences between the two groups. Generally, the estimates for applicants to the most popular programs tend to be a little bit larger.

\subsection{A Discussion of the Underlying Mechanisms}

We began our analysis with an investigation of the effects of the admission system on college enrollment decisions. Given that we have now also established that the admission system affects family formation decisions, we would like to elaborate a little bit on this issue, since it is crucial for interpretation of the estimates. It is not that interesting in itself that the admission system affects family formation. The interesting question is why the admission system affects family formation. Does it induce differences in the timing of enrollment across individuals? Does it induce differences in the type of college program attended? Or both?

While we cannot give a definitive answer to this question, we can interpret the empirical evidence at hand. The enrollment graphs in Figure 3 clearly suggest that the admission system has substantial effects on the timing of college enrollment, but only modest effects, if any, on enrollment in a specific program. Timing of enrollment may affect subsequent family formation decisions in a number of ways. The main point is that the timing of college enrollment is likely to determine the timing of many other career milestones, such as college completion and labor market entry. The timing of college enrollment is also likely to matter for an individual's future income stream. However, the choice of college program may also matter for future income and other aspects of life, e.g. marriage market opportunities, peers, social norms, which could all be expected to affect family formation decisions. 
To corroborate our claim that the admission system affects mainly the timing of college enrollment, we consider two additional outcomes, namely college completion and earnings. Figure 10 shows the estimated effects of being above the admission requirement on college completion and earnings. Specifically, college completion is defined as having completed at least a three-year college program. ${ }^{17}$ In the short run, i.e. 3-4 years after YOA, there is a substantial positive effect on college completion of being above the admission requirement as we would expect. Individuals above the admission requirement enroll earlier on average and this translates into earlier college completion. In the long run, the estimates show that being above the admission requirement does not have a significant effect on the probability of completing college. Thus, differences in family formation behavior may be attributed to the timing of college completion, but not to whether you ever complete college. The graph is consistent with the notion that the main effect of the admission system is to delay some individuals in their educational career, but not to alter their career path as such.

Figure 10 also shows the estimated effects of being above the admission requirement on earnings. If individuals rank college programs according to earnings potential, and the college program realization differs for individuals below and above the admission requirement, we would expect individuals above the admission requirement to end up with higher earnings, ceteris paribus. Higher earnings are usually considered to increase one's value on the marriage market. As such, the differences in timing of family formation could be caused by differences in the expected match quality of individuals below and above the admission requirement. The graph shows that there is a naturally negative effect on earnings in the first year after YOA, since those who do not enroll typically 'take a year off' to work, implying that they have high earnings compared to college students. In addition, there are positive and more or less significant effects of being above the admission requirement on earnings 2-8 years after YOA. During this period, individuals who are above the admission requirement will be further ahead in their career. The size of the estimated effects is relatively small, and increases somewhat after 6 years when many of the individuals above the admission requirement will have graduated from college and entered the labor market.

\footnotetext{
${ }^{17}$ This measure is chosen in order to have a comparable measure across college programs and to minimize problems with right censoring. Most long-cycle programs actually consist of two parts: A three-year degree and a two-year degree on top of that. The vast majority of college graduates from the long-cycle programs complete both degrees.
} 
Thus, the result that being above the admission requirement speeds up family formation can to some extent be driven by differences in the earnings trajectories. In this case earnings have a positive effect on the demand for children. In the long-run there is no significant effect of being above the admission requirement on earnings. Again this is consistent with the other evidence that we have presented and suggests that the admission system mainly affects the timing of college enrollment. $^{18}$

To sum up, we have presented a variety of empirical evidence that is consistent with the admission system affecting the timing of college enrollment. We cannot definitively rule out that there are no effects of the admission system on the choice of specific college program. If we are willing to assume that only the timing of college enrollment is affected, we can estimate the effect of delayed college enrollment on family formation decisions by instrumental variables (IV).

\subsection{The Effect of Timing of College Enrollment on Family Forma-}

\section{tion}

Under the assumption that being above the admission requirement affects family formation only through the effect on timing of enrollment, we can estimate the effect of enrolling in YOA on later family formation outcomes. We simply instrument whether or not you enroll in YOA with the indicator for being above the admission requirement. Figure 11 shows the resulting IV estimates which basically correspond to the reduced form estimates divided by the jump in enrollment. Not surprisingly, we find a pattern similar to that found for the reduced form estimates. For marriage the effects tend to be insignificant with a few exceptions. For number of children the estimated effects are generally positive, significant, and relatively large. For example, the effect of enrolling in the YOA on number of children 10 years after YOA is about 0.3 . This should be seen relative to a sample mean of about 0.6 , implying that enrolling in the YOA increases the number of children 10 years later by 50 percent. We usually assume that responses are heterogeneous, and in this case the IV estimate can only be given a Local Average Treatment Effect (LATE) interpretation. In this case, LATE is a relevant policy parameter, since policy makers are able to change exactly

\footnotetext{
${ }^{18}$ Another potential explanation is that there are very small differences in the monetary returns to college programs.
} 
this margin by e.g. alleviating the capacity constraints in the different college programs.

The estimates depicted in Figure 11 show a significant effect of timing of enrollment on number of children as soon as about 4 years after YOA. This roughly coincides with the time where individuals who do not delay enrollment begin to enter the labor market. This suggests that one of the channels through which timing of enrollment affects family formation is the timing of labor market entry. One reason for this could be that individuals want to postpone having children until they have established a labor market career. This would be consistent with Del Bono, Weber, and Winter-Ebmer (2012) who find that career oriented women who are laid off after a plant closure delay having children. We also found that the admission system appeared to have larger effects on women, cf. Figure 6. It is reasonable that women are more affected by institutions and policies that affect childbearing since they tend to incur the largest costs-pecuniary and non-pecuniaryof childbearing. Relatedly, Björklund (2006) argues that the family policies in Sweden create an incentive for women to delay childbearing until they have finished their education and established themselves in the labor market. This is also a valid point in Denmark where, for example, the eligibility for high maternity leave benefits is conditional on a certain degree of attachment to the labor market.

\subsection{Robustness}

In this section we explore the robustness of our main results with respect to the estimation window and a placebo analysis.

\subsubsection{Window Size}

The choice of window size is potentially very important. Figure 12 shows how sensitive the estimates are to smaller changes in the size of the window. The full lines correspond to the estimates in Figure 5 with a window of 0.3. Almost all estimates using different window sizes are well within the 95 percent confidence bands of the main estimates. As expected the confidence bands widen as the window is reduced and the number of observations becomes smaller. 


\subsubsection{Placebo Estimates}

In a type of placebo analysis, we pretend that the admission requirement is 0.6 GPA units above the real admission requirement and re-estimate our empirical model. Figure 13 shows the regular estimates as reported in Figure 5 and the placebo estimates. The placebo estimates are much closer to zero and are generally insignificant at a 5 percent level.

\section{Conclusion}

We analyze the effects of the college admission system in Denmark on family formation decisions. In doing so, we establish that the admission system has its primary effect on the timing of college enrollment. Therefore, we are able to provide evidence on a problem that has not been paid much attention in the literature on educational choices, namely how delays in the educational career affect the timing of family formation and especially fertility decisions. Other studies have sought to estimate effects of education on family formation, but they have focused on earlier educational interventions such as rules regarding school starting age and compulsory schooling laws that may have both timing and human capital effects.

We find strong evidence that being above the admission requirement affects the timing of later family formation decisions. The estimated effects tend to be substantial. We find that being above the admission requirement increases the number of children 8 years after YOA by about 0.1, i.e. about 40 percent. The overall pattern of the estimates suggests that being above the admission requirement speeds up family formation. We cannot observe completed fertility for this sample, but during the period for which data is currently available, we see that individuals just below and above the admission requirement tend to converge in terms of the probability of being married and being a parent. However, for number of children there appear to be more long-lasting effects.

To understand the mechanisms behind the effects of the admission system on family formation, we analyze in detail the effects of the admission system on college enrollment decisions, college completion and earnings. These analyses clearly suggest that the admission system affects family formation mainly through the timing of college enrollment. Using the admission system as an instrument for the timing of college enrollment, we can estimate the effect of enrolling in 
the YOA on later family formation outcomes. Again, we find substantial effects: The effect of enrolling in the YOA on number of children 10 years after YOA is about 0.3 . This corresponds to an increase of about 50 percent.

Theoretically, our results are consistent with several underlying explanations. First, potential parents may wish to smooth consumption and therefore postpone parenthood until they reach a certain income level. Secondly, career-oriented individuals may want to establish themselves on the labor market before starting a family.

From a policy perspective, our results highlight another potential cost of educational policies that induce delays or interruptions in the educational career, namely delayed family formation and childbearing. Many educational policies potentially affect not only the human capital formation of children and youth, but also the timing of that human capital, e.g., school entry rules, compulsory schooling laws etc. Our study highlights the importance of considering other consequences of educational policies than just the 'pure' human capital effects. Also, if lowering the age at first birth and increasing fertility rates are policy objectives, our results suggest that providing incentives for individuals to progress faster in the educational system might be desirable. In the specific context of delayed college enrollment, policy makers may want to consider how to increase incentives to enroll earlier, e.g., by increasing the quality of guidance counseling in high school.

\section{References}

BECKER, G. (1965): “A theory of the allocation of time,” Economic Journal, 75, 493-517.

BECKER, G. S., AND H. G. LEWIS (1973): “On the Interaction between the Quality and Quantity of Children," Journal of Political Economy, 81, 279-288.

Becker, G. S., AND N. Tomes (1976): "Child Endowments and the Quantity and Quality of Children," Journal of Political Economy, 84, 143-162.

BJÖRKLUND, A. (2006): “Does family policy affect fertility?,” Journal of Population Economics, 19(1), 3-24. 
Black, S. E., P. J. Devereux, And K. G. Salvanes (2008): "Staying in the Classroom and out of the maternity ward? The effect of compulsory schooling laws on teenage births," Economic Journal, 118(530), 1025-1054.

Black, S. E., P. J. Devereux, And K. G. Salvanes (2011): “Too Young to Leave the Nest? The Effects of School Starting Age," The Review of Economics and Statistics, 93(2), 455-467.

Bozick, R., AND S. DeLuCA (2005): "Better Late than Never? Delayed Enrollment in the High School to College Transition," Social Forces, 84, 531-554.

Cammelli, A., G. Antonelli, A. Di Francia, G. Gasperoni, And M. SGarzi (2011): in Employment and mobility of bachelor graduates in Europe. Key results of the Bologna Process, ed. by H. Schomburg, and U. Teichlerchap. Mixed outcomes of the Bologna Process in Italy, pp. 143-170. Rotterdam: Sense Publishers.

Ciliberto, F., A. Miller, H. S. Nielsen, And M. Simonsen (2013): "Playing the Fertility Game at Work: An Equilibrium Model of Peer Effects," Available at SSRN: http://ssrn.com/abstract=2242606 or http://dx.doi.org/10.2139/ssrn.224260.

Currie, J., AND E. Moretti (2003): “Mother's education and the intergenerational transmission of human capital: Evidence from college openings.," Quarterly Journal of Economics, $118(4), 1495-1532$.

D’Addio, A. C., And M. M. D'Ercole (2005): “Trends and Determinants of Fertility Rates: The Role of Policies," OECD Social, Employment and Migration Working Papers 27, OECD Publishing.

Del Bono, E., A. Weber, AND R. Winter-Ebmer (2012): "Clash of career and family: Fertility decisions after job displacement," Journal of the European Economic Association, 10(4), 659-683.

Devereux, P. J., AND G. TRIPATHi (2009): “Optimally combining censored and uncensored datasets," Journal of Econometrics, 151(1), 17 - 32. 
Feyrer, J., B. Sacerdote, AND A. D. Stern (2008): "Will the Stork Return to Europe and Japan? Understanding Fertility within Developed Nations," Journal of Economic Perspectives, $22(3), 3-22$.

Fort, M., N. Schneeweis, And R. Winter-Ebmer (2011): “More Schooling, More Children: Compulsory Schooling Reforms and Fertility in Europe," IZA DP, (No. 6015).

Goldin, C., And L. Katz (2002): “The Power of the Pill: Oral Contraceptives and Women's Career and Marriage Decisions," Journal of Political Economy, 110(4), 730-770.

GRÖNQVIST, H., AND C. HALL (2013): "Education policy and early fertility: Lessons from an expansion of upper secondary schooling," Economics of Education Review, 37(0), 13 - 33.

HAPpel, S. K., J. K. Hill, And S. A. LOW (1984): “An Economic Analysis of the Timing of Childbirth,” Population Studies, 38(2), pp. 299-311.

Holmlund, B., Q. LiU, AND O. N. SKans (2008): "Mind the Gap? Estimating the Effects of Postponing Higher Education," Oxford Economic Papers, 60(4), 683-710.

Horn, L., E. F. CATAldi, A. Sikora, AND C. D. CARroll (2005): "Waiting to Attend College: Undergraduates Who Delay Their Postsecondary Enrollment (NCES 2005 152)," Discussion paper, U.S. Department of Education, National Center for Education Statistics, Washington, DC: Government Printing Office.

Imbens, G. W., And T. Lemieux (2008): “Regression discontinuity designs: A guide to practise," Journal of Econometrics, 142(2), 615-635.

KuZIEmKo, I. (2006): “Is Having Babies Contagious? Estimating Fertility Peer Effects Between Siblings," Mimeo, Harvard University.

LeE, D. S., AND T. Lemieux (2010): “Regression Discontinuity Designs in Economics," Journal of Economic Literature, 48(2), 281-355. 
LERIDON, H., AND R. Slama (2008): “The impact of a decline in fecundity and of pregnancy postponement on final number of children and demand for assisted reproduction technology," Human Reproduction, 23(6), 1312-1319.

MCCrary, J., AND H. Royer (2011): "The Effect of Female Education on Fertility and Infant Health: Evidence from School Entry Laws Using Exact Date of Birth," American Economic Review, 101(1), 158-195.

Monstad, K., C. Propper, And K. G. Salvanes (2008): "Education and fertility: Evidence from a natural experiment," Scandinavian Journal of Economics, 110(4), 827-852.

ÖCKERT, B. (2010): “What's the value of an acceptance letter? Using admissions data to estimate the return to college," Economics of Education Review, 29(4), 504 - 516.

Silles, M. (2011): "The effect of schooling on teenage childbearing: evidence using changes in compulsory education laws," Journal of Population Economics, 24, 761-777.

SkirbekK, V., H.-P. Kohler, And A. Prskawetz (2004): "Birth Month, School Graduation, and the Timing of Births and Marriages," Demography, 41(3), 547-568.

te Velde, E., D. Habbema, H. Leridon, And M. Eijkemans (2012): “The effect of postponement of first motherhood on permanent involuntary childlessness and total fertility rate in six European countries since the 1970s," Human Reproduction, 27(4), 1179-1183. 


\section{A Figures}

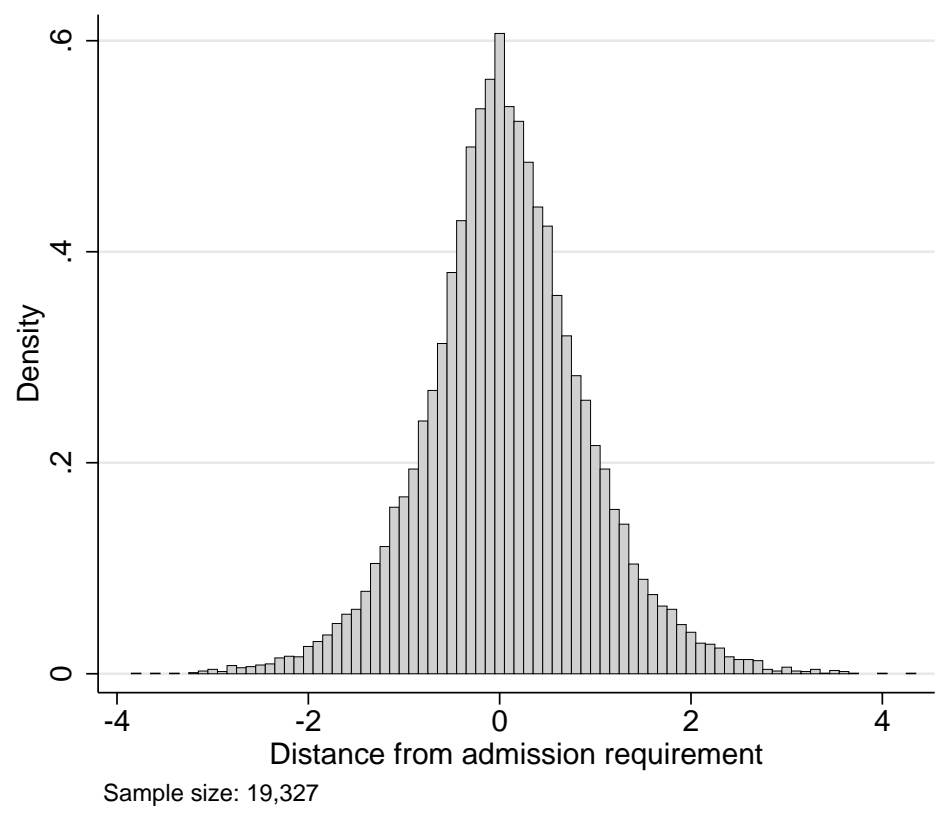

Figure 1: Distribution of distance from admission requirement. 

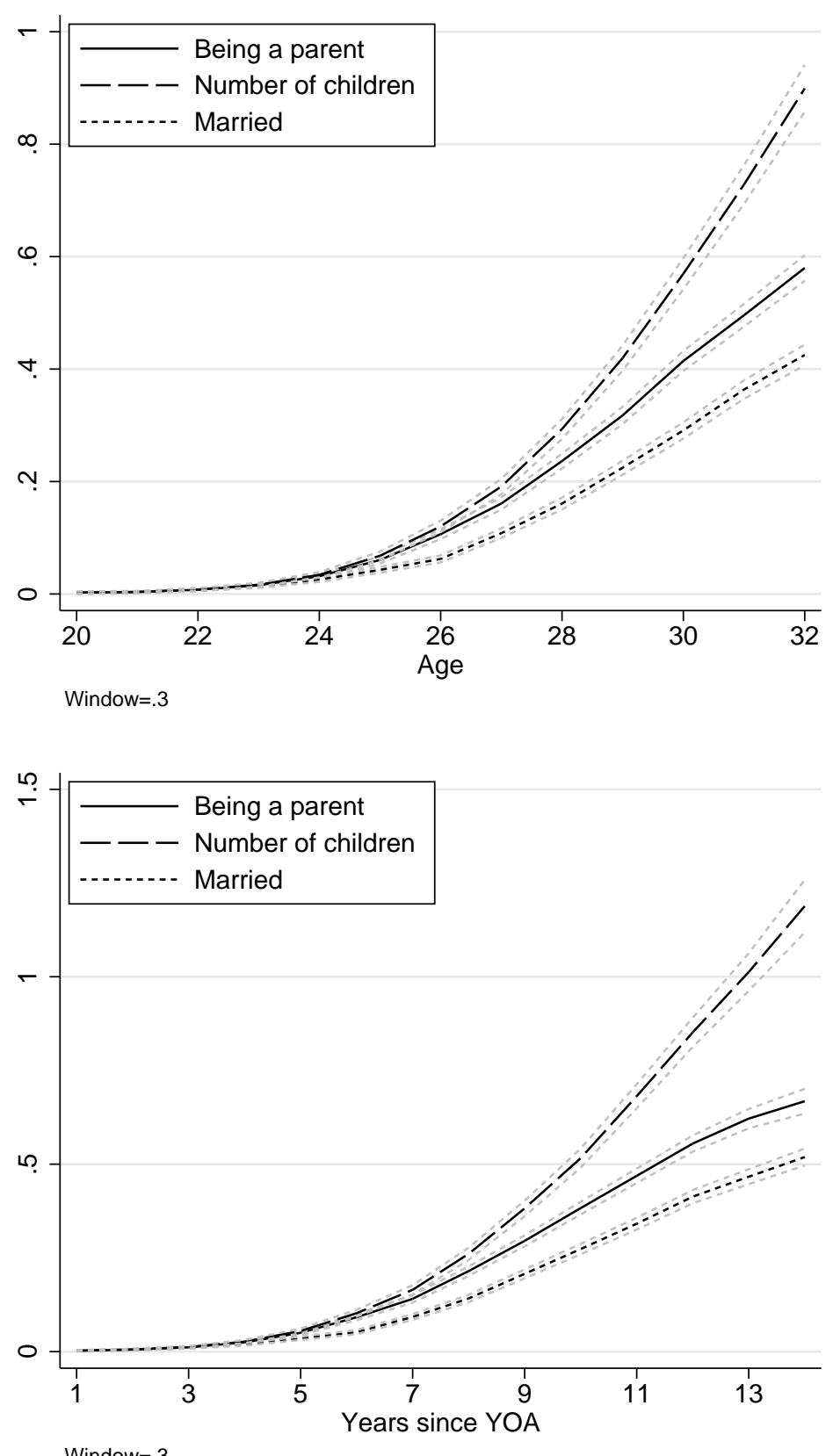

Window $=.3$

Figure 2: Probability of being a parent, being married, and number of children by age and YOA. 95 percent confidence bands. 

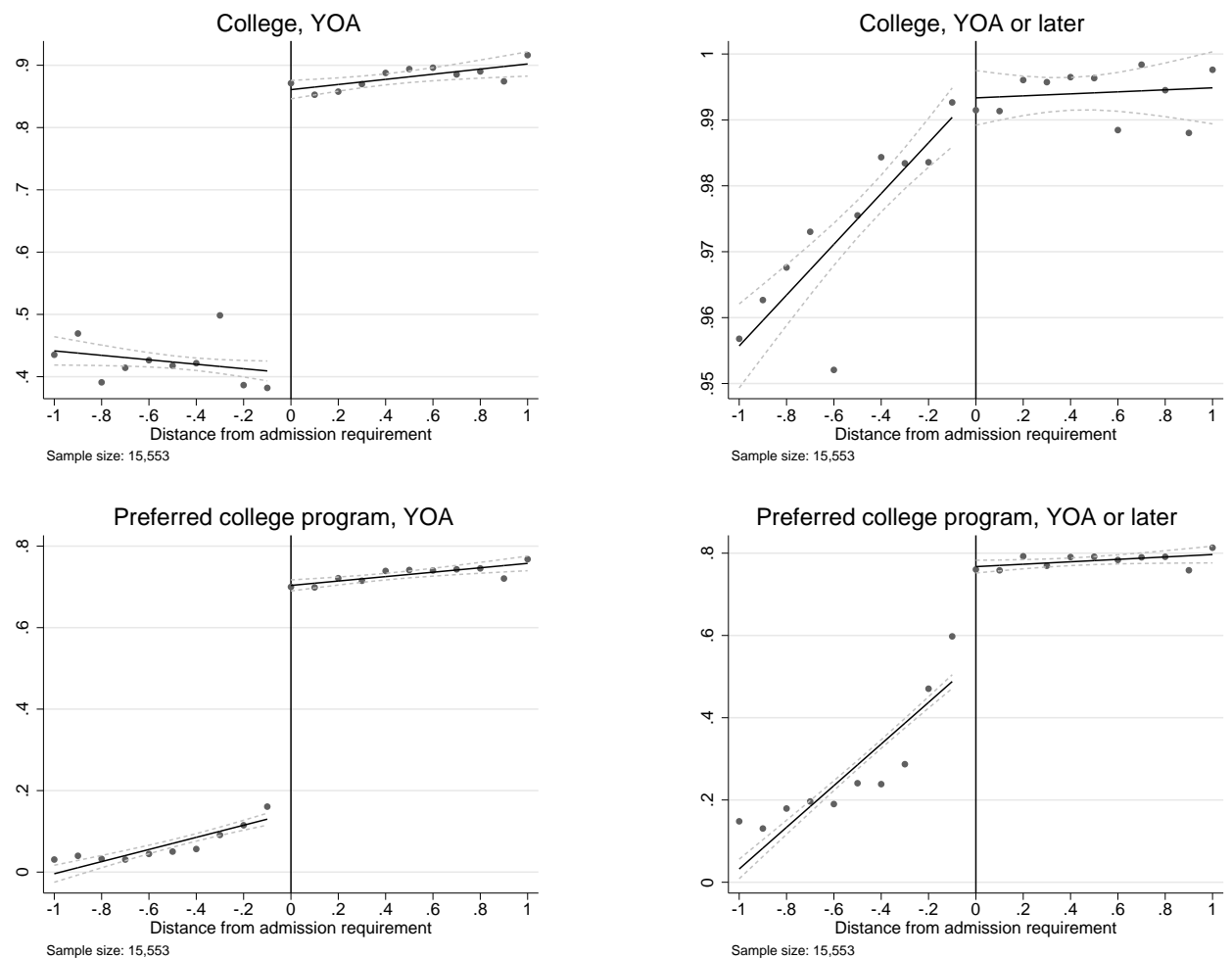

Figure 3: College enrollment by distance from admission requirement. Scatter plots are overlaid with fitted values and 95 percent confidence bands from a linear regression on distance, an indicator for being above the admission requirement, and an interaction of the two. 

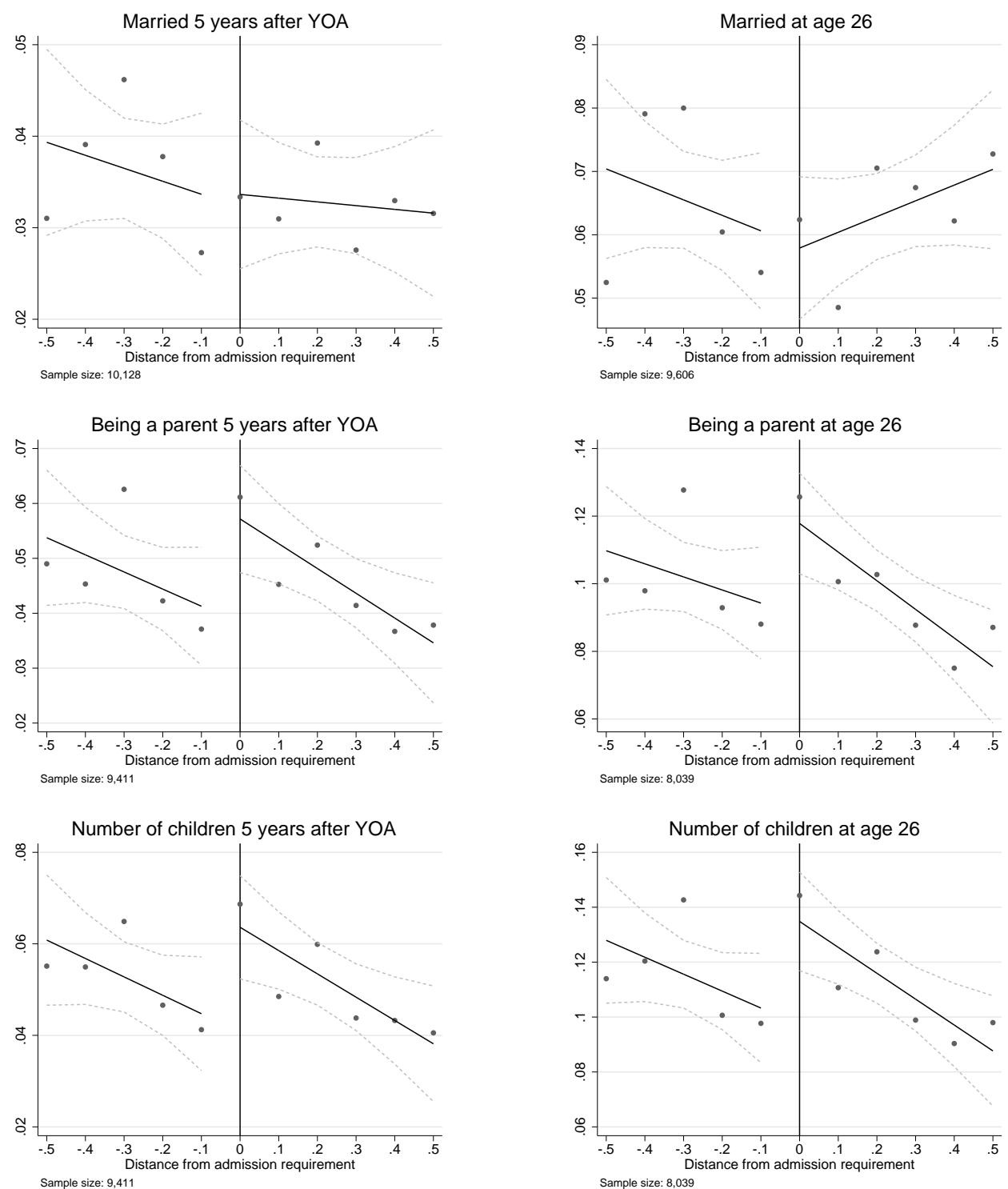

Figure 4: Selected outcomes by distance from admission requirement. Scatter plots are overlaid with fitted values and 95 percent confidence bands from a linear regression on distance, an indicator for being above the admission requirement, and an interaction of the two. 

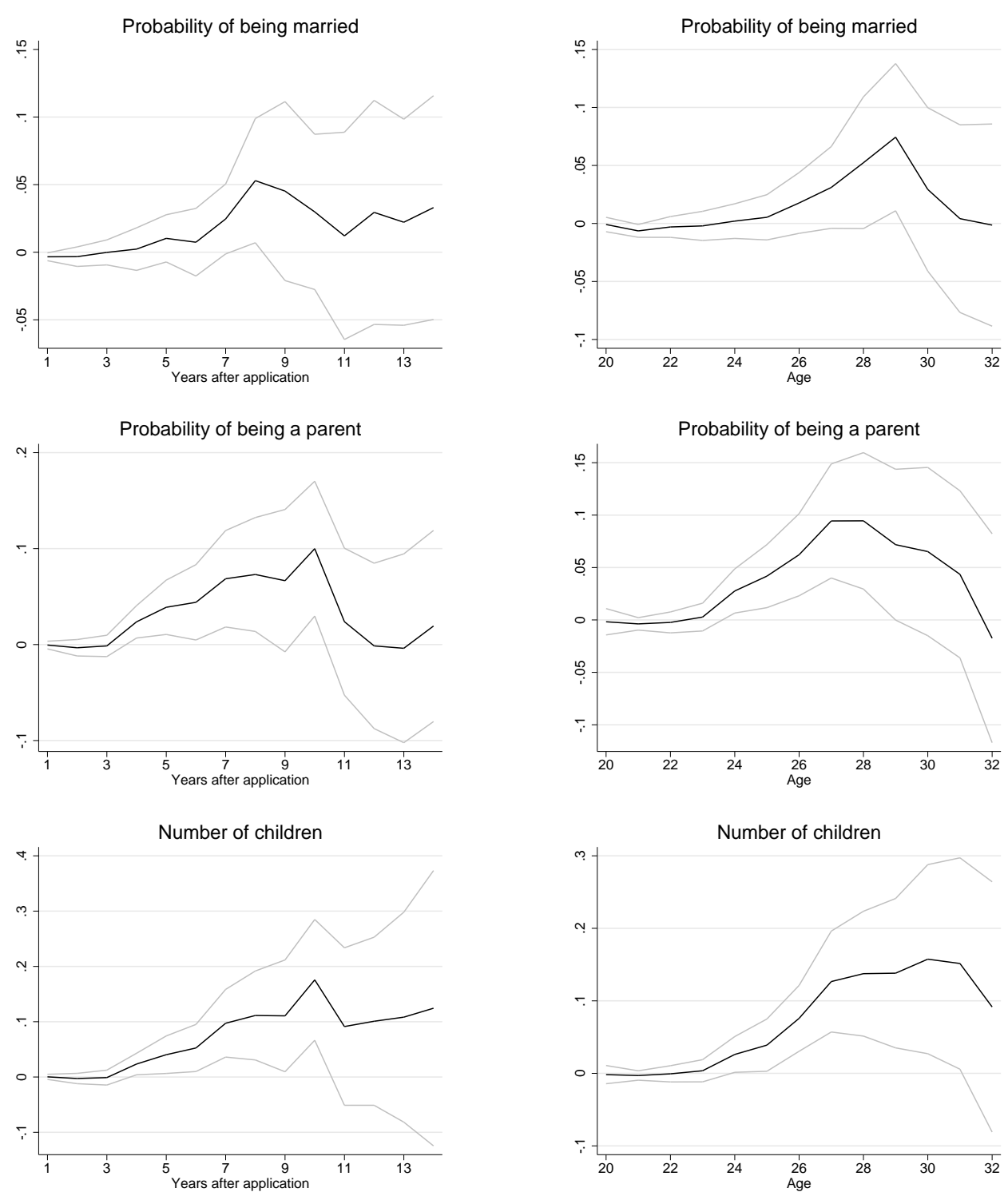

Figure 5: Reduced form estimates of the effect of being above the admission requirement on main outcomes and 95 percent confidence bands. Includes all covariates. Standard errors are clustered the college program level. 

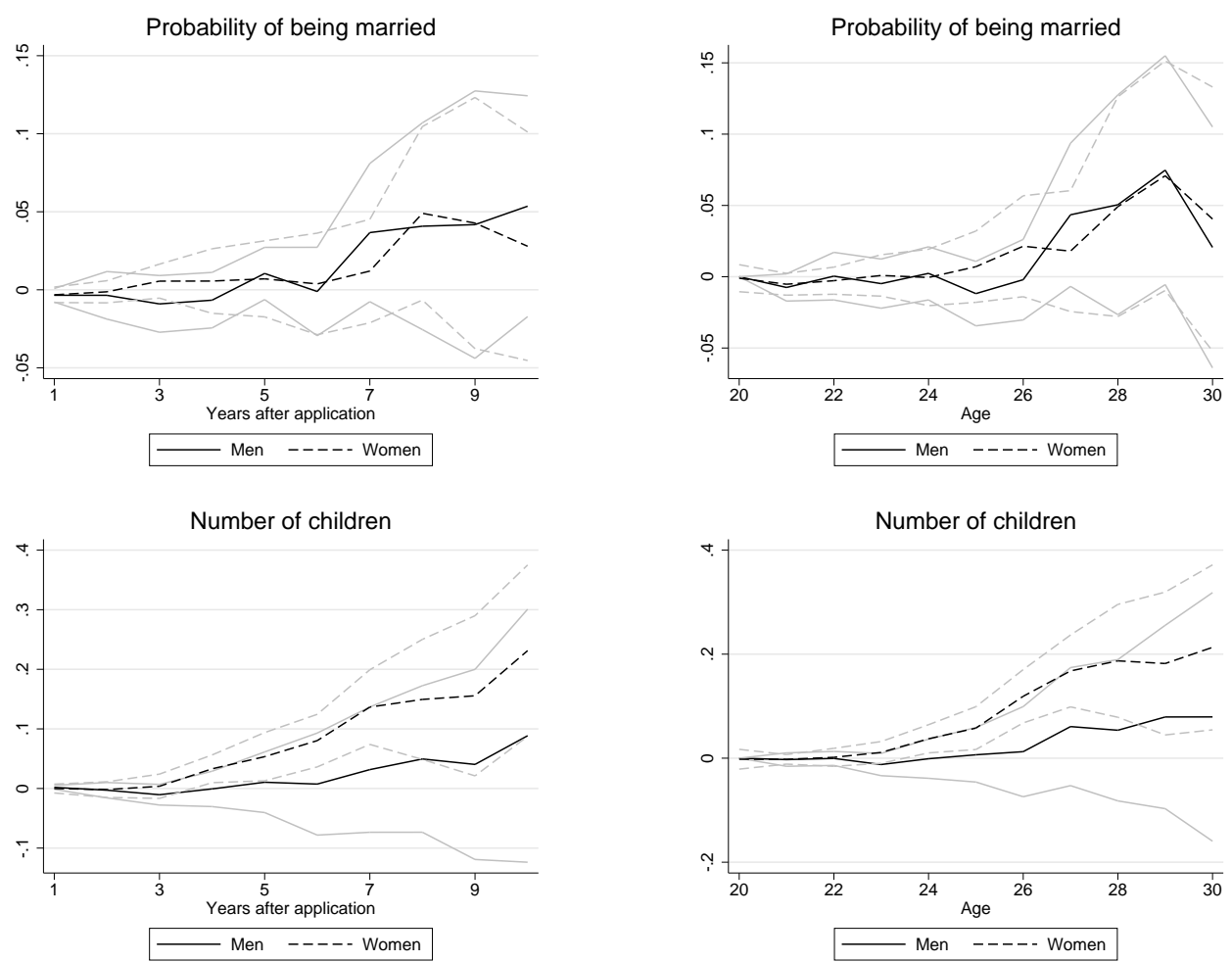

Figure 6: Reduced form estimates of the effect of being above the admission requirement on main outcomes and 95 percent confidence bands by gender. Includes all covariates. Standard errors are clustered at the college program level. 

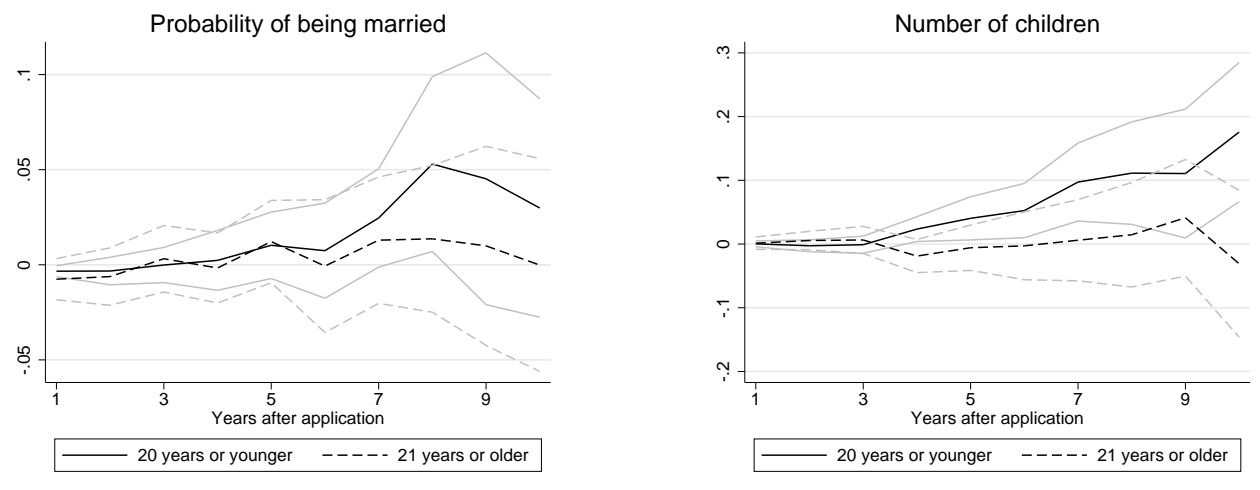

Figure 7: Reduced form estimates of the effect of being above the admission requirement on main outcomes and 95 percent confidence bands by age in YOA. Includes all covariates. Standard errors are clustered at the college program level. 

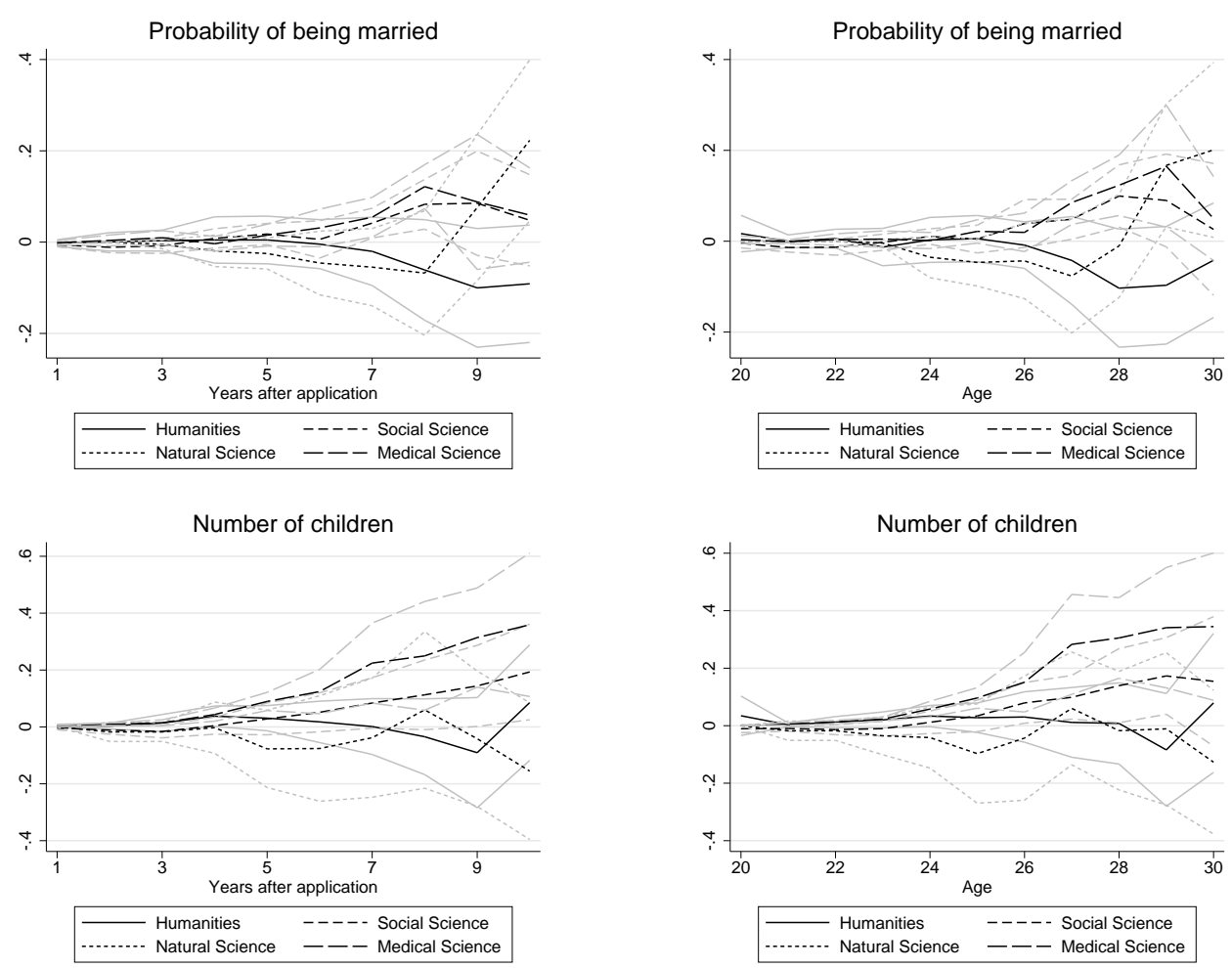

Figure 8: Reduced form estimates of the effect of being above the admission requirement on main outcomes and 95 percent confidence bands by field of preferred college program. Includes all covariates. Standard errors are clustered at the college program level. 

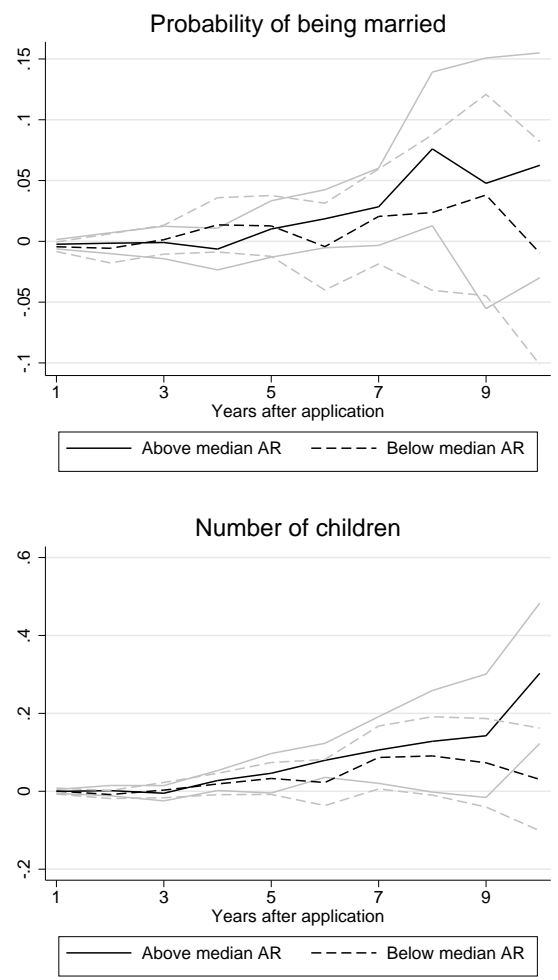
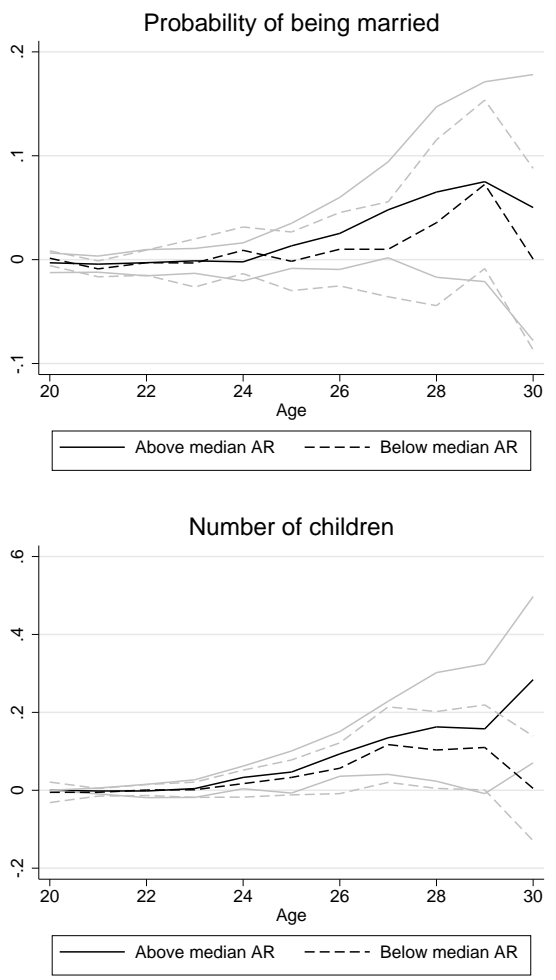

Figure 9: Reduced form estimates of the effect of being above the admission requirement on main outcomes and 95 percent confidence bands by admission requirement (AR) of preferred college program. Includes all covariates. Standard errors are clustered at the college program level. 
Probability of having completed a college program (long)
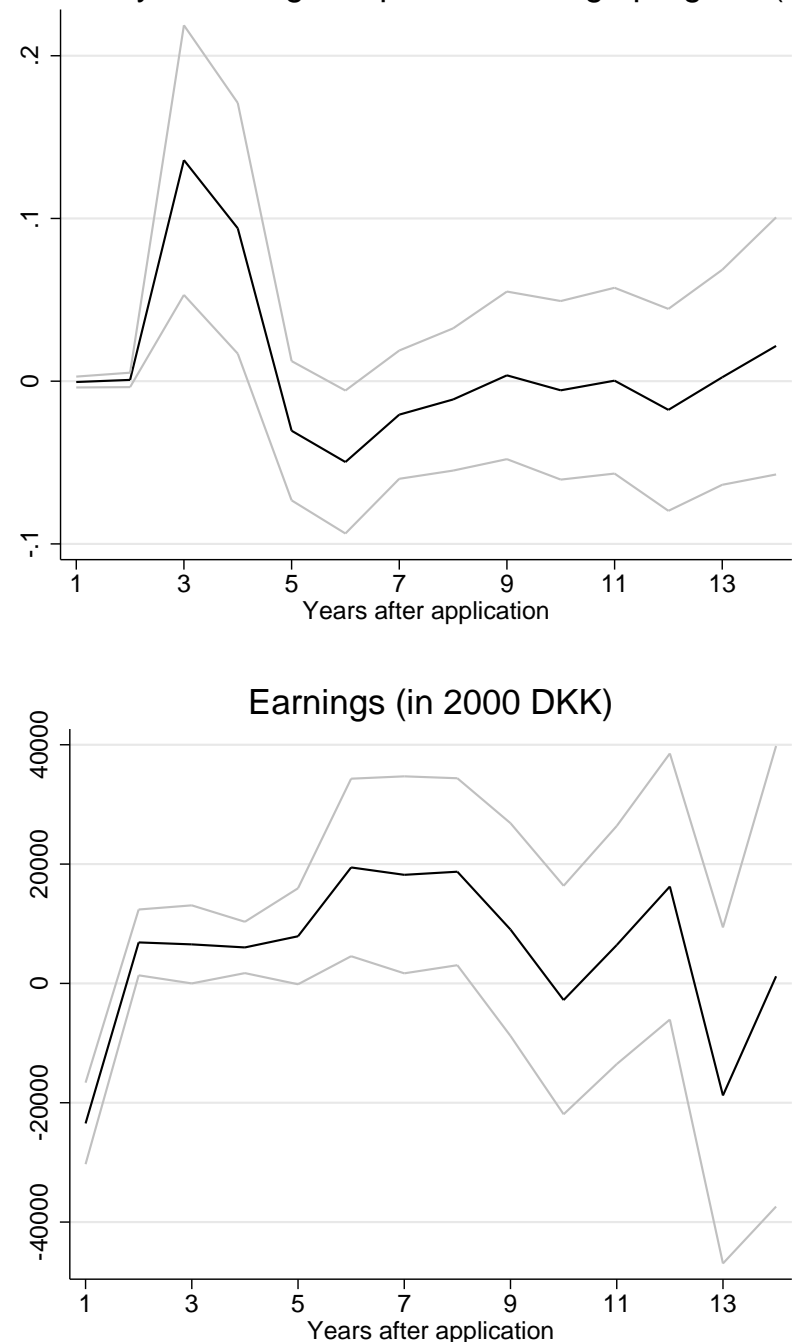

Figure 10: Reduced form estimates of the effect of being above the admission requirement on college completion and earnings and 95 percent confidence bands. Includes all covariates. Standard errors are clustered at the college program level. 

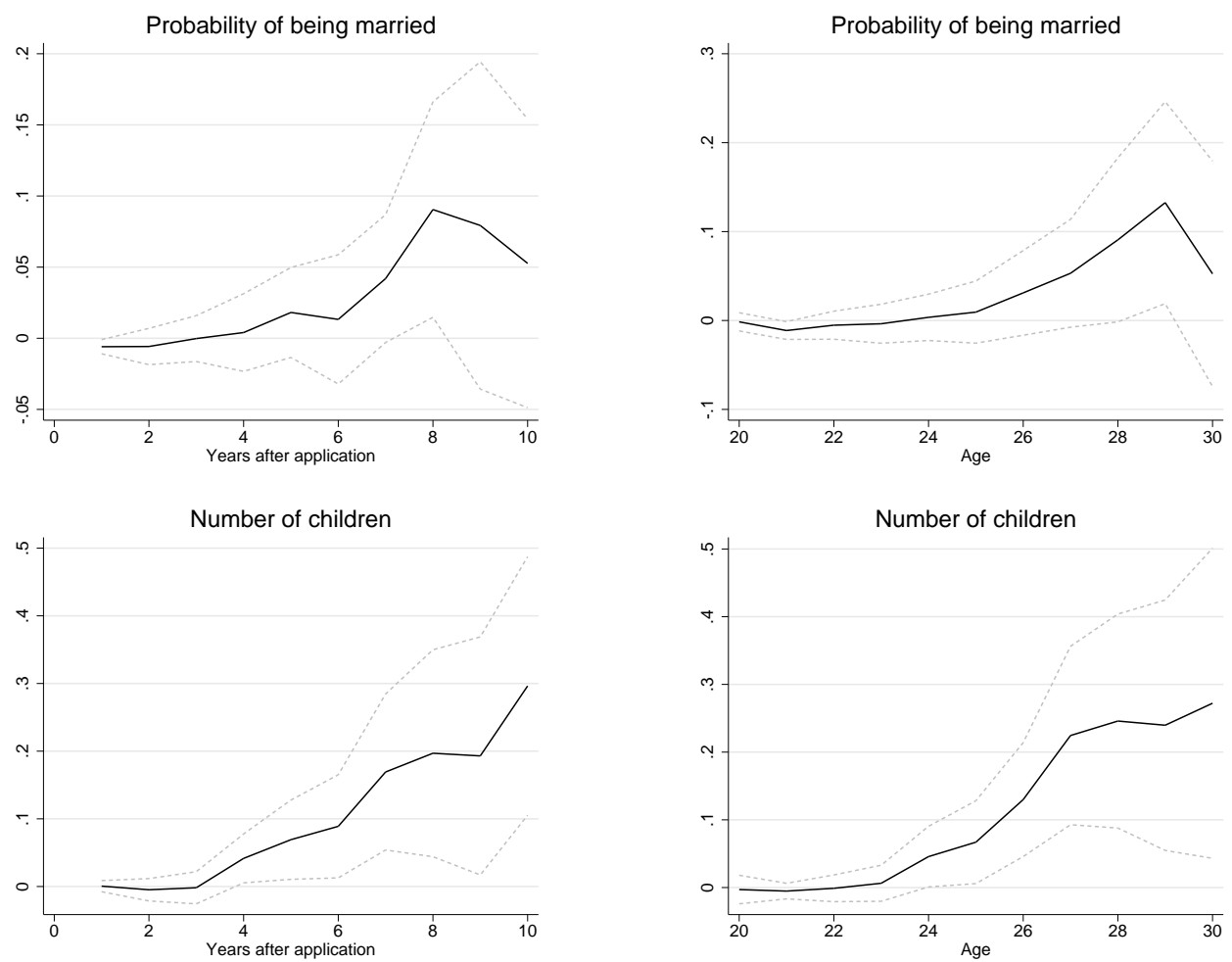

Figure 11: IV estimates of the effect of enrollment in YOA on main outcomes and 95 percent confidence bands. Includes all covariates. Standard errors are clustered at the college program level 

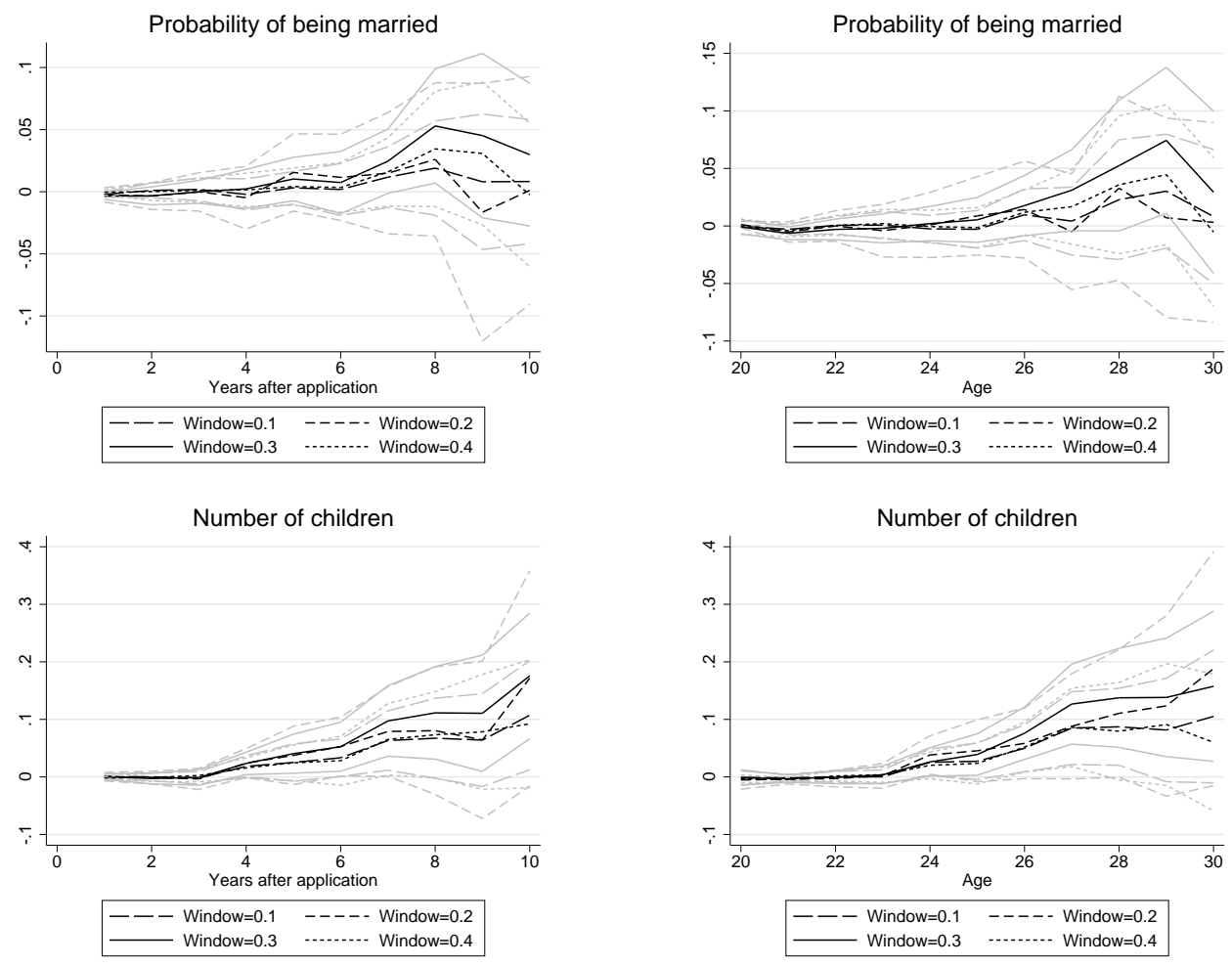

Figure 12: Reduced form estimates of the effect of being above the admission requirement on main outcomes and 95 percent confidence bands for varying window widths. Includes all covariates. Standard errors are clustered at the college program level. 

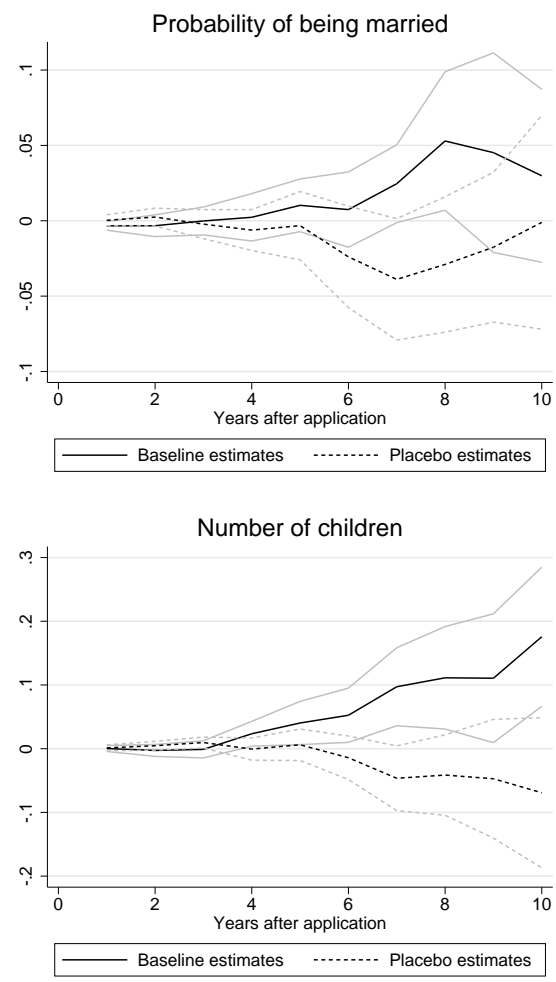
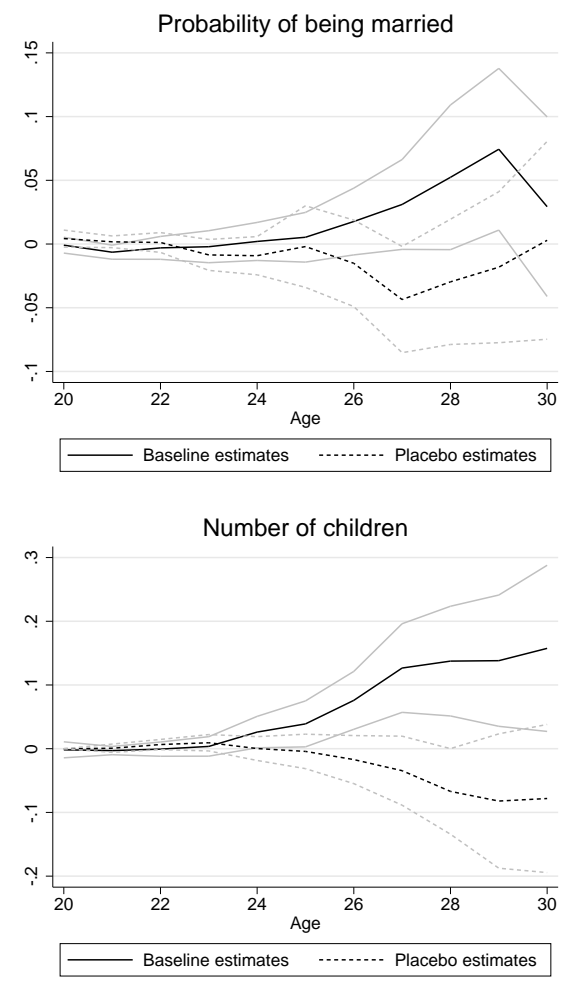

Figure 13: Placebo reduced form estimates of the effect of being above the admission requirement on main outcomes and 95 percent confidence bands. Placebo distance is defined as distance from the admission requirement minus 0.6. Includes all covariates. Standard errors are clustered at the college program level 


\section{B Tables}

Table 1: SAmple SELECtion

\begin{tabular}{lrr}
\hline \hline Description & $\begin{array}{r}\text { Number of } \\
\text { observations }\end{array}$ & $\begin{array}{r}\text { Percentage } \\
\text { of total }\end{array}$ \\
\hline Applications to college programs 1996-2006 & 621,695 & 100.0 \\
Applications to college (long) & 288,531 & 46.4 \\
First application & 195,576 & 31.5 \\
The preferred college program has a grade requirement & 133,735 & 21.5 \\
The preferred college program has a simple enrollment rule & & \\
for those who exactly meet the grade requirement & 66,871 & 10.8 \\
Non-missing GPA & 44,945 & 7.2 \\
Young applicants & 19,327 & 3.1 \\
& & \\
Window=0.3 & 6,313 & 1.0 \\
\hline \hline
\end{tabular}


Table 2: Descriptive StATISTICS

\begin{tabular}{|c|c|c|c|c|c|c|}
\hline & \multicolumn{2}{|c|}{$\begin{array}{c}\text { Below } \\
\text { admission requirement }\end{array}$} & \multicolumn{2}{|c|}{$\begin{array}{c}\text { Above } \\
\text { admission requirement }\end{array}$} & \multicolumn{2}{|c|}{ Test for jump } \\
\hline & Mean & Std. dev. & Mean & Std. dev. & Coef. & p-value \\
\hline \multicolumn{7}{|l|}{ Controls } \\
\hline Female & 0.673 & & 0.657 & & 0.004 & 0.849 \\
\hline Age in YOA & 19.643 & $(0.538)$ & 19.651 & $(0.544)$ & 0.001 & 0.972 \\
\hline \multicolumn{7}{|l|}{ Mother's age at birth } \\
\hline$<25$ & 0.161 & & 0.167 & & 0.022 & 0.290 \\
\hline 25 to 34 & 0.718 & & 0.697 & & -0.056 & $0.007 * * *$ \\
\hline$>34$ & 0.109 & & 0.124 & & 0.025 & $0.047^{* *}$ \\
\hline Missing & 0.013 & & 0.012 & & 0.009 & $0.062 *$ \\
\hline \multicolumn{7}{|l|}{ Father's age at birth } \\
\hline$<25$ & 0.065 & & 0.060 & & 0.007 & 0.532 \\
\hline 25 to 34 & 0.659 & & 0.659 & & -0.001 & 0.957 \\
\hline$>34$ & 0.247 & & 0.243 & & -0.015 & 0.432 \\
\hline Missing & 0.029 & & 0.038 & & 0.009 & 0.276 \\
\hline \multicolumn{7}{|l|}{ Mother's education } \\
\hline Basic & 0.178 & & 0.185 & & 0.006 & 0.683 \\
\hline Vocational & 0.228 & & 0.220 & & 0.013 & 0.511 \\
\hline College & 0.547 & & 0.555 & & -0.024 & 0.392 \\
\hline Missing & 0.047 & & 0.040 & & 0.005 & 0.650 \\
\hline \multicolumn{7}{|l|}{ Father's education } \\
\hline Basic & 0.156 & & 0.165 & & 0.016 & 0.403 \\
\hline Vocational & 0.227 & & 0.225 & & 0.019 & 0.258 \\
\hline College & 0.531 & & 0.518 & & -0.051 & $0.066^{*}$ \\
\hline Missing & 0.086 & & 0.092 & & 0.016 & 0.235 \\
\hline Mother missing & 0.013 & & 0.012 & & 0.009 & $0.062^{*}$ \\
\hline Father missing & 0.029 & & 0.038 & & 0.009 & 0.276 \\
\hline Mother's log earnings at age 18 & 10.670 & $(4.276)$ & 10.733 & $(4.193)$ & -0.153 & 0.488 \\
\hline Mother's earnings missing & 0.031 & & 0.027 & & 0.008 & 0.424 \\
\hline Father's log earnings at age 18 & 12.643 & $(1.021)$ & 12.681 & $(0.937)$ & 0.074 & $0.050^{*}$ \\
\hline Father's earnings missing & 0.213 & & 0.225 & & 0.041 & $0.009^{* * *}$ \\
\hline Prior enrollments & 0.008 & & 0.010 & & 0.001 & 0.779 \\
\hline Being a parent in YOA & 0.000 & & 0.001 & & 0.000 & 0.990 \\
\hline Cohabiting in YOA & 0.025 & & 0.025 & & -0.006 & 0.454 \\
\hline - Missing & 0.026 & & 0.024 & & -0.020 & $0.013^{* *}$ \\
\hline
\end{tabular}

This table continues on the next page. 
Table 2 - continued from previous page.

\begin{tabular}{|c|c|c|c|c|c|c|}
\hline & \multicolumn{2}{|c|}{$\begin{array}{l}\text { Below } \\
\text { admission requirement }\end{array}$} & \multicolumn{2}{|c|}{$\begin{array}{c}\text { Above } \\
\text { admission requirement }\end{array}$} & \multicolumn{2}{|c|}{ Test for jump } \\
\hline & Mean & Std. dev. & Mean & Std. dev. & Coef. & p-value \\
\hline \multicolumn{7}{|l|}{ College application and enrollment } \\
\hline High school GPA & 8.945 & $(0.554)$ & 9.180 & $(0.465)$ & 0.001 & 0.721 \\
\hline \multicolumn{7}{|l|}{ Preferred field } \\
\hline Humanities & 0.246 & & 0.283 & & n.a. & \\
\hline Social Science & 0.404 & & 0.391 & & n.a. & \\
\hline Natural Science & 0.076 & & 0.081 & & n.a. & \\
\hline Medical Science & 0.274 & & 0.245 & & n.a. & \\
\hline Enrolled in YOA & 0.420 & & 0.861 & & 0.563 & $0.000 * * *$ \\
\hline Enrolled in YOA or later & 0.987 & & 0.993 & & -0.007 & $0.097^{*}$ \\
\hline Enrolled in preferred program in YOA & 0.124 & & 0.706 & & 0.507 & $0.000 * * *$ \\
\hline Enrolled in preferred program in YOA or later & 0.458 & & 0.770 & & -0.008 & 0.759 \\
\hline \multicolumn{7}{|l|}{ Selected outcomes } \\
\hline Being a parent 5 years after YOA & 0.047 & & 0.053 & & 0.040 & $0.007 * * *$ \\
\hline No. of children 5 years after YOA & 0.050 & $(0.235)$ & 0.059 & $(0.261)$ & 0.041 & $0.019 * *$ \\
\hline Married 5 years after YOA & 0.037 & & 0.034 & & 0.012 & 0.185 \\
\hline Being a parent at age 26 & 0.102 & & 0.110 & & 0.065 & $0.001 * * *$ \\
\hline No. of children at age 26 & 0.113 & $(0.350)$ & 0.127 & $(0.382)$ & 0.079 & $0.001 * * *$ \\
\hline Married at age 26 & 0.064 & & 0.061 & & 0.018 & 0.163 \\
\hline Number of observations & 3,089 & & 3,224 & & 6,313 & \\
\hline
\end{tabular}

Notes:

a) '***', ${ }^{* *}{ }^{\prime}$, and ${ }^{\prime}{ }^{\prime}$ ' indicate statistical significance at the 1,5 , and 10 percent levels, respectively.

b) In the analyses in section 5 , we include indicators for age in stead of the continuous variable.

c) For a couple of the variables listed the number of observations differs from the size of the estimation sample:

Mother's log earnings: 6,130; and father's log earnings: 4,931. For the selected outcomes, see Table 4.

d) To test for a jump, each covariate is regressed on $t_{i}, d_{i}$, and an interaction of the two. The coefficient and

corresponding p-value are reported. Preferred college program-year fixed effects are included and standard errors are clustered at the college program level. 
Table 3: Heterogeneous EfFects of the Admission System on ENROLlMEnt

\begin{tabular}{|c|c|c|c|c|c|}
\hline \multirow[t]{2}{*}{ Enrollment } & & \multicolumn{2}{|l|}{ College } & \multicolumn{2}{|c|}{ Preferred college program } \\
\hline & & YOA & YOA or later & YOA & YOA or later \\
\hline & No. of obs. & Coef./Std. Err. & Coef./Std. Err. & Coef./Std. Err. & Coef./Std. Err. \\
\hline Estimation sample & 6,313 & $\begin{array}{l}0.563 * * * \\
(0.034)\end{array}$ & $\begin{array}{l}-0.007 \\
(0.006)\end{array}$ & $\begin{array}{l}0.507 \text { *** } \\
(0.035)\end{array}$ & $\begin{array}{r}-0.008 \\
(0.027)\end{array}$ \\
\hline \multicolumn{6}{|l|}{ Subgroups } \\
\hline Men & 2,116 & $\begin{array}{l}0.567 * * * \\
(0.051)\end{array}$ & $\begin{array}{l}-0.002 \\
(0.008)\end{array}$ & $\begin{array}{l}0.503 * * * \\
(0.050)\end{array}$ & $\begin{array}{r}-0.019 \\
(0.046)\end{array}$ \\
\hline Women & 4,197 & $\begin{array}{l}0.562 * * * \\
(0.037)\end{array}$ & $\begin{array}{l}-0.015^{* *} \\
(0.007)\end{array}$ & $\begin{array}{l}0.512 \text { *** } \\
(0.037)\end{array}$ & $\begin{array}{r}0.001 \\
(0.032)\end{array}$ \\
\hline 20 years or younger & 6,313 & $\begin{array}{l}0.563 \text { *** } \\
(0.034)\end{array}$ & $\begin{array}{l}-0.007 \\
(0.006)\end{array}$ & $\begin{array}{l}0.507 * * * \\
(0.035)\end{array}$ & $\begin{array}{r}-0.008 \\
(0.027)\end{array}$ \\
\hline 21 years or older & 7,304 & $\begin{array}{l}0.272 * * * \\
(0.028)\end{array}$ & $\begin{array}{l}-0.005 \\
(0.008)\end{array}$ & $\begin{array}{l}0.372 * * * \\
(0.029)\end{array}$ & $\begin{array}{l}0.088^{* * * *} \\
(0.024)\end{array}$ \\
\hline Humanities & 1,670 & $\begin{array}{l}0.512^{* * * *} \\
(0.054)\end{array}$ & $\begin{array}{l}-0.015^{* *} \\
(0.007)\end{array}$ & $\begin{array}{l}0.519^{* * *} \\
(0.048)\end{array}$ & $\begin{array}{r}0.095 \\
(0.058)\end{array}$ \\
\hline Social Science & 2,511 & $\begin{array}{l}0.607 \text { *** } \\
(0.052)\end{array}$ & $\begin{array}{r}-0.006 \\
(0.012)\end{array}$ & $\begin{array}{l}0.659^{* * * *} \\
(0.043)\end{array}$ & $\begin{array}{l}-0.001 \\
(0.032)\end{array}$ \\
\hline Natural Science & 496 & $\begin{array}{l}0.352 \text { *** } \\
(0.110)\end{array}$ & $\begin{array}{r}0.008 \\
(0.022)\end{array}$ & $\begin{array}{l}0.211^{* *} \\
(0.101)\end{array}$ & $\begin{array}{r}-0.154 \\
(0.103)\end{array}$ \\
\hline Medical Science & 1,636 & $\begin{array}{l}0.595^{* * *} \\
(0.069)\end{array}$ & $\begin{array}{l}-0.007 \\
(0.006)\end{array}$ & $\begin{array}{l}0.352^{* * * *} \\
(0.083)\end{array}$ & $\begin{array}{r}-0.060 \\
(0.061)\end{array}$ \\
\hline Below median AR & 3,083 & $\begin{array}{l}0.519 \text { *** } \\
(0.052)\end{array}$ & $\begin{array}{r}-0.004 \\
(0.011)\end{array}$ & $\begin{array}{l}0.480 * * * \\
(0.054)\end{array}$ & $\begin{array}{r}0.013 \\
(0.036)\end{array}$ \\
\hline Above median AR & 3,230 & $\begin{array}{l}0.597 \text { *** } \\
(0.044)\end{array}$ & $\begin{array}{l}-0.009 * * \\
(0.004)\end{array}$ & $\begin{array}{l}0.527 * * * \\
(0.048)\end{array}$ & $\begin{array}{r}-0.022 \\
(0.039)\end{array}$ \\
\hline
\end{tabular}

\section{Notes:}

a) '***', '**', and '*' indicate statistical significance at the 1,5 , and 10 percent levels, respectively. b) To test for a jump, each covariate is regressed on $t_{i}, d_{i}$, and an interaction of the two. The coefficient and standard errors are reported. Preferred college program-year fixed effects are included and standard errors are clustered at the college program level. 
Table 4: Reduced Form Estimates of the Effect of Being Above the Admission Requirement on SeLECTED FAMILY FORMATION OUTCOMES

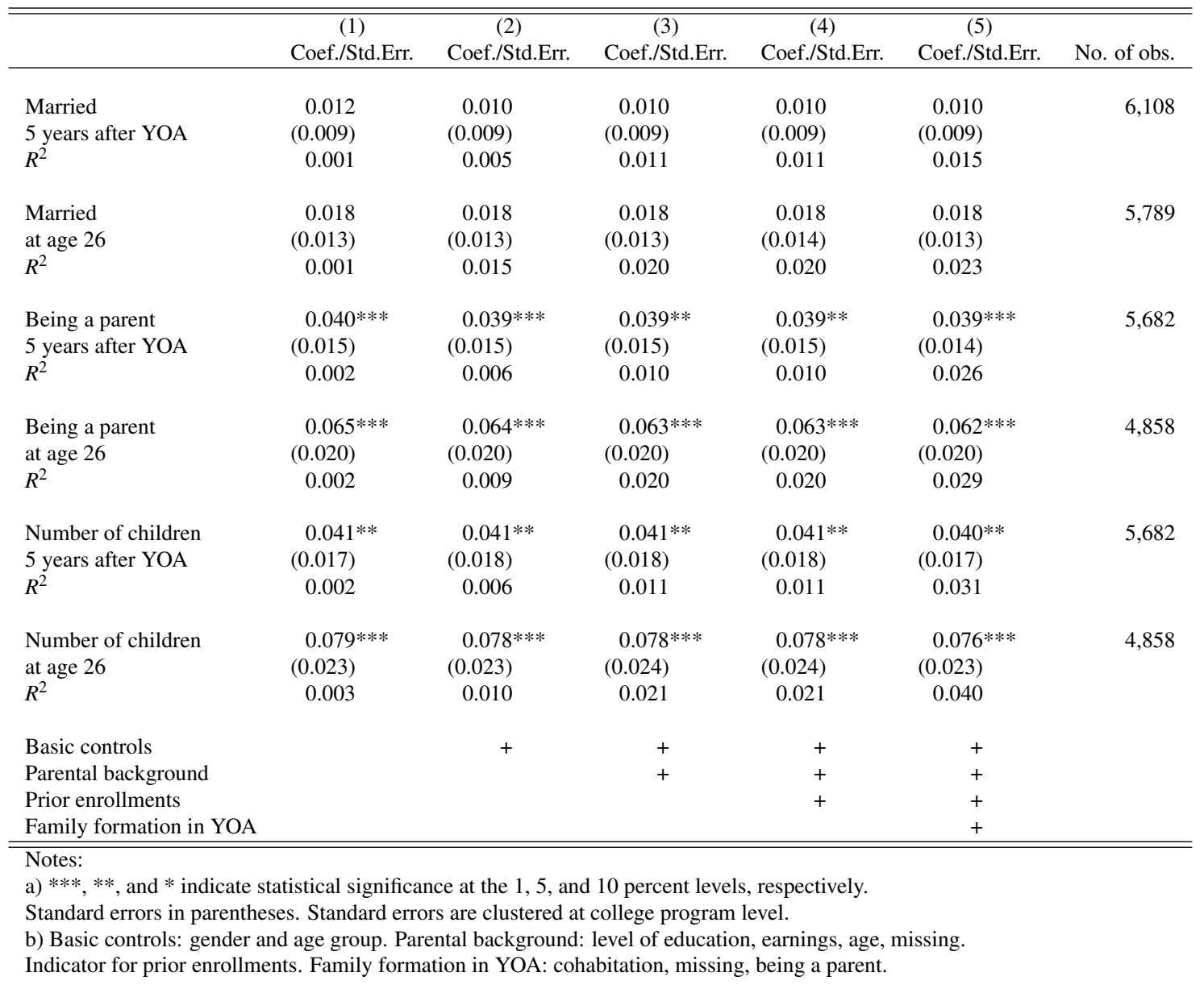

